\title{
STATISTICAL ANALYSIS \\ OF A DETERMINATION \\ OF THE HALF LIFE OF KRYPTON-85
}

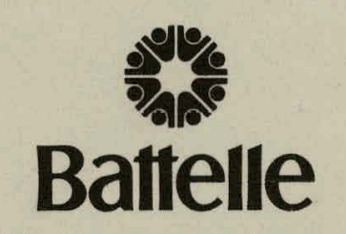

Pacific Northwest Laboratories

Richland, Washington 99352

JULY 24, 1974

Prepared for the U.S. Atomic Energy

Commission under Contract AT(45-1):1830

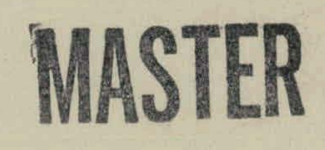




\section{DISCLAIMER}

This report was prepared as an account of work sponsored by an agency of the United States Government. Neither the United States Government nor any agency Thereof, nor any of their employees, makes any warranty, express or implied, or assumes any legal liability or responsibility for the accuracy, completeness, or usefulness of any information, apparatus, product, or process disclosed, or represents that its use would not infringe privately owned rights. Reference herein to any specific commercial product, process, or service by trade name, trademark, manufacturer, or otherwise does not necessarily constitute or imply its endorsement, recommendation, or favoring by the United States Government or any agency thereof. The views and opinions of authors expressed herein do not necessarily state or reflect those of the United States Government or any agency thereof. 


\section{DISCLAIMER}

Portions of this document may be illegible in electronic image products. Images are produced from the best available original document. 
NOTICE

The report was prepared as an account of work sponsored by the United States Government. Neither the United States nor the United States Atomic Energy Commission, nor any of their employees, nor any of their contractors, subcontractors, or their employees, makes any warranty, express or implied, or assumes any legal liability or responsibility for the accuracy, completeness or usefulness of any information, apparatus, product or process disclosed, or represents that its use would not infringe privately owned rights.

\author{
PACIFIC NORTHWEST LABORATORY \\ operated by \\ BATTELLE \\ for the \\ U.S. ATOMIC ENERGY COMMISSION \\ Under Contract AT(45-1)-1830
}

\author{
Printed in the United States of America \\ Available from \\ National Technical Information Service \\ U.S. Department of Commerce \\ 5285 Port Royal Road \\ Springfield, Virginia 22151 \\ Price: Printed Copy $\$ 5.45$; Microfiche $\$ 1.45$
}




\title{
STATISTICAL ANALYSIS OF A DETERMINATION \\ OF THE HALF LIFE OF KRYPTON-85
}

by

\author{
James W. Johnston
}

July 24, 1974

This report was prepared as an account of work sponsored by the United States Government. Neither the United States nor the United States Atomic Energy Commictinn, nor any of thrir cmplnyess, nor any of their contractors, subcontractors, or their employees, makes any warranty, express or implied, or assumes any makes any warranty, express or implied, or assumes any

pleteness or usefulness of any information, apparatus, pleteness or usefulness of any information, apparatus,
product or process disclosed, or represents that its use product or process disclosed, or represents that its use
would not infringe privately owned rights.

\section{BATTELLE \\ PACIFIC NORTHWEST LABORATORIES \\ RICHLAND, WASHINGTON}




\section{CONTENTS}

$\begin{array}{lc} & \text { PAGE } \\ \text { SUMMARY } & 1 \\ \text { DATA BASE AND NOTATION } & 2 \\ \text { RATIO CALCULATIONS AND HALF-LIFE ESTIMATION PROCEDURE } & 4 \\ \text { DATA EDITING } & 7 \\ \text { ESTIMATION MODELS } & 8 \\ \text { RESULTS OF FITTING THE ESTIMATION MODELS } & 11 \\ \text { AVERAGE HALF-LIFE ESTIMATE } & \ddots \\ \text { NOTE ON CORRECTION FOR RADIUM DECAY } & 21 \\ \text { APPENDIX: LISTING AND SUMMARIES OF DATA } & 25\end{array}$

LIST OF TABLES

1. Statistics For Model 2

2. Model 2 Compared to Model 3 E and Model 3 
STATISTICAL ANALYSIS OF A DETERMINATION

OF THE HALF LIFE OF KRYPTON-85

\section{SUMMARY}

Data from 53 determinations of $\mathrm{Kr}^{85}$ to $\mathrm{Ra}^{226}$ ratios done over a 15 -year long experiment to determine the half-life of $\mathrm{kr}^{85}\left(\mathrm{~K}_{1 / 2}\right)$ were analyzed. A number of least squares regression models were fitted to the data. The best fitting model:produced a $\mathrm{K}_{1 / 2}$ of 10.715 years with a standard deviation of 0.008 years. An average half-life estimate, based on individual half-life estimates from 48 of the $\mathrm{Kr} / \mathrm{Ra}$ ratios was also calculated to show the effect on the uncertainty of estimation. The average half-life method produced a $K_{1 / 2}$ estimate of 10.714 years with a propagated standard deviation of 0.0565 years.

The uncertainty associated with the regression estimate could have been reduced by greater care for consistency in the ionization chamber set-up. It was found that use of a glass sample holder for the earlier determinations and a plastic sample holder for 11 of the later determinations increased the uncertainty but apparently did not bias the results. The broad fluctuation of counting times from determination to determination, caused by use of capacitors with different capacitance, also contributed to the less than optimum precision.

It was also found that the temperature/pressure adjustment used had no significant effect on the results. That is, the ratios are not significantly different when calculated with or without the T/P correction. However, including the changes in the average $T / P$ from determination to determination did produce a significant reduction in the uncertainty of estimation. 
DATA BASE AND NOTATION

The study to experimentally determine the half-life of krypton 85 began on $2 / 13 / 58$ and there were 53 "determinations" through $1 / 5 / 73$, a period spanning about 1.5 nominal half-lives (10.76 years). For the purpose of this study a "determination" will be defined as the set of runs, done on a study day, used in the determination of a radium/krypton ratio. Each determination consisted of a variable number of runs in the $4 \pi \gamma$ ionization chamber on each of the radium and. krypton samples plus blank runs to determine background. Temperature and pressure were also recorded a variable number of times during the determination. The usual experimental procedure was to do a single background (B) run, 3 to 6 runs on the radium (R) standard, 4 to 10 runs on the krypton (K) sample, another 3 to 6 radium runs and a final background run, all using NBS's $4 \pi \gamma$ ionization chamber. This B-R-K-R-B design accounted for 43 of the 53 determinations; the $R-B-K-B-R$ design was used 5 times, the $R-B-K-R-B$ design 2 times and the $R-B-K-K-R-B$, the $R-K-R-B$ and $B-R-B-K-B-R-B$ designs were each used once. At the end of the experiment there was a series of 11 determinations which used a plastic instead of a glass sample holder. The same radium and krypton samples were used. The first 6 of these determinations using the plastic holder had associated determinations using the glass holder on the same day or within 10 days.

The following notation will be used to describe the data and analysis and to discuss the results. The datum recorded for each run in the ionization chamber was the length of time required to charge a capacitor 
(equivalent to the waiting time to the $m^{\text {th }}$ count). Let $x_{v i j k}$ be the waiting time observed on the

$k^{\text {th }}$ run, $k=1, \ldots, k_{v i j}, k_{v i j} \leqq 10$, within the

$j^{\text {th }}$ set of runs, $j=1, \ldots, J_{v i}, J_{v i} \leqq 2$, in the

$i^{\text {th }}$ determination, $i=1, \ldots, 53$ on the

$v^{\text {th }}$ sample, where $v=1$ for a background run,

$v=2$ for a radium run,

$v=3$ for a krypton run.

Also, let

$D_{i}$ be the number of days from the start of the study to the day on which the $i^{\text {th }}$ determination was done,

$T_{v i j k}$ ' and $P_{v i j k}$ ' be the $k^{\prime}$ th temperature and pressure readings, respectively, recorded for the $j^{\text {th }}$ set of runs on day $i$,

$E_{v i j}$ be the temperature/pressure ratio adjusted from degrees centigrade to degrees Kelvin, $E_{v i j}=\left(\bar{T}_{v i j} .+273.16 / \bar{P}_{v i j .}\right.$, where summation for the averages $\bar{T}_{v i j}$. and $\bar{P}_{v i j}$. is over' those $k$ ' recorded during, or between, the ion chamber runs for $B, K$ or $R$, according as $v$ is 1,2 or 3 ,

$c_{i j}$ be the correction factor for putting the background readings on the same counting basis as the radium and krypton readings.

The capacitor and the background run setting for the ionization chamber were changed from determination to determination so that the average counting times vary widely over the study period. The background averages 
$\left(\bar{x}_{1 i} ..\right)$ varied from about 2 to 13 minutes, the average times for the radium sample $\left(\bar{x}_{2 i} ..\right)$ varied from 14 seconds to almost 3 minutes, the averages of the runs on the krypton sample $\left(\bar{x}_{3 i} ..\right)$ varied from 20 seconds to 2.4 minutes.

A listing of the basic data is given in the Appendix.

\section{RATIO CALCULATIONS AND HALF-LIFE ESTIMATION PROCEDURE}

Given the above basic data, the following calculations were done for each determination.

$$
\begin{aligned}
\rho_{1 i} & =\frac{\bar{x}_{2 i . .}}{\bar{x}_{3 i . .}}=\frac{\text { Average elapsed time for the Ra runs }}{\text { Average elapsed time for the } k r \text { runs }} \\
\rho_{2 i} & =\left[1 / \bar{X}_{3 i 1}-B_{i}\right] /\left[1 / \bar{x}_{2 i . .}-B_{i}\right] \\
& =\frac{\text { Net Counting Rate for } k r}{\text { Net Counting Rate for Ra }} \\
\rho_{3 i} & =\left[\frac{\bar{E}_{3 i .}}{\bar{x}_{3 i 1}}-B_{i}\right] /\left[\frac{1}{2}\left(\frac{\bar{E}_{2 i 1}}{\bar{x}_{2 i 1}}+\frac{\bar{E}_{2 i 2 .}}{\bar{x}_{2 i 2}}\right)-B_{i j}\right] \\
& =\frac{\text { Temperature \& Pressure Corrected Net Counting Rate for } K r}{\text { Temperature \& Pressure Corrected Net Counting Rate for Ra }}
\end{aligned}
$$

where

$$
\begin{aligned}
& B_{i}=1 / 2\left[c_{i 1} / \bar{x}_{1 i 1}+c_{i 2} / \bar{x}_{1 i 2 .}\right], \\
& B E_{i}=1 / 2\left[c_{i 1} E_{1 i 1} / \bar{x}_{1 i 1}+c_{i 2} E_{1 i 2} / \bar{x}_{1 i 2 .}\right] .
\end{aligned}
$$

The average temperature-pressure correction for the $i^{\text {th }}$ determination was also calculated as 


$$
E_{i}=\sum_{v j} E_{v i j} / \sum_{v} J_{v i}
$$

The resuits of the above intermediate calculations were used to make both regression and average estimates of the half-life of K-85. The theory involved is as follows.

At determination $i$ the essential data were:

$D_{i}$, the time from the start of the experiment in days, $\bar{x}_{1 i \ldots}$, the adjusted average background time, $\bar{x}_{2 i},$. , the average time to record $m_{i}$ radium counts, and $\bar{x}_{3 i} \ldots$, the average time to record $m_{i}$ krypton counts.

Given that there are $N_{v i}$ atoms present at the start of counting on day $D_{i}$ the disintegration rate is $\lambda_{v}{ }_{v i}$ per second $\left(\lambda_{v}\right.$ in seconds), and $\bar{X}_{v i}$.. is the waiting time to record the $m_{i}$ th count, $m_{i}$ being the same for both the radium and krypton samples. Then, defining $\eta_{v}$ as the counter efficiency factor,

$$
m_{i}=\left(n_{v} \lambda_{v} N_{v i}\right) \bar{x}_{v i} . . \text { or } \frac{m_{i}}{\bar{x}_{v i} . .}=\eta_{v} \lambda_{v} N_{v i} ; v=2,3 \text { or } R, k
$$

and assuming the counter efficiencies remain in constant ratio

$$
r=n_{3} / n_{2}
$$

over the 15-year study span,

$$
i=\frac{\bar{x}_{3 i . . \lambda_{K} N_{K i}}}{\bar{x}_{2 i} . \lambda_{R} N_{K i}} r
$$

so that

1. A more detailed general exposition is available in: Stevenson, P.C., Processing of Counting Data, Nat' 1 Academy of Science - Nat'l Research Council, May 1966; (NAS-NS 3109), particularly pp. 3,4. 


$$
\frac{\lambda_{K} N_{K i}}{\lambda_{R} N_{R i}} r=\frac{1 / \bar{X}_{3 i}}{1 / \bar{X}_{2 i}}=\rho_{i} \text {. }
$$

Substituting the decay equations.

$$
N_{R i}=N_{R 0} \exp \left[-\lambda_{R} \cdot D_{i}\right]
$$

and

$$
N_{K i}=N_{K O} \exp \left[\begin{array}{ll}
-\lambda_{K} & D_{i}
\end{array}\right]
$$

we get

$$
\begin{aligned}
\rho_{i} & =r \frac{\lambda_{K} N_{K O} \exp \left[-\lambda_{K} D_{i}\right]}{\lambda_{R} N_{R O} \exp \left[-\lambda_{R} D_{i}\right]} \\
& =\frac{m_{0} / \bar{X}_{3 i} . .}{m_{0} / \bar{X}_{2 i} .} \exp \left[-\left(\lambda_{K}-\lambda_{R}\right) D_{i}\right] . \\
& =\rho_{0} \exp \left[-\left(\lambda_{K}-\lambda_{R}\right) D_{i}\right] .
\end{aligned}
$$

This relationship remains valid as long as the ratio of the counting efficiencies does not change. Then

$$
\ln \rho_{\mathbf{i}}=\ln \rho_{0}-\left(\lambda_{K}-\lambda_{R}\right) D_{i}
$$

The end products of each of the 53 determinations were the ratios $\rho_{j}$, adjusted for background and temperature/pressure. The relationship of Eq. (1) is linear so that fitting the line

$$
y=\alpha+\beta D_{i}
$$

with $y=\ln \rho_{i}$, will provide an estimate of $\beta$. Now

$$
\beta=\lambda_{R}-\lambda_{K}
$$

so that

$$
\hat{\lambda}_{K}=\lambda_{R}-\hat{\beta} \text {. }
$$


[Note that a shift in the ratio, $r$, of efficiencies would only affect the intercept, through $\rho_{0}$, and not the slope.]

Since $\lambda_{R}$ is known $\left(1.17 \times 10^{-6} /\right.$ day $)$, each ratio determination also provides an estimate of the half-life, as follows from Eq. (1),

$$
\begin{aligned}
\hat{\lambda}_{K i} & =\left(\ln \rho_{0}-\ln \rho_{i}+\lambda_{R} D_{i}\right) / D_{i} \\
& =\left(\ln \rho_{0}-\ln \rho_{i}\right) / D_{i}+\lambda_{R} .
\end{aligned}
$$

Then, for either the regression or individual determination methods,

$$
K_{1 / 2}=\ln 2 / \hat{\lambda}_{K}
$$

\section{DATA EDITING}

The first three determinations (done on $2 / 13 / 58,5 / 15 / 59$, and $3 / 1 / 60$ ) were handled separately because the experimental setup was different (a voltmeter, rather than a capacitor, was used to control the counting time) and because the sequence of sets of runs was different for the first and second determinations.

The $28^{\text {th }}$ determination, done on $2 / 12 / 65$, had a large discrepency between the averages for the two sets of radium runs, and resulted in a ratio that was larger than the previous ratio, done 67 days earlier, and a between radium set standard deviation of 5.408 . The $39^{\text {th }}$ determination, done on $9 / 5 / 68$, had a smaller discrepancy between the sets of radium runs $(s d=1.457)$, but the ratio was smaller than the following ratio, done 77 
days later. The next largest between radium set standard deviation was 0.318 and the between set standard deviation, pooled over the 48 remaining capacitor determinations, was 0.152. $\left[F(1,48)=\frac{(1.457)^{2}}{(0.152)^{2}}=91.88\right.$ has a probability of occurrence of less than 0.0001 under the assumption that the between radium sets averages for the $39^{\text {th }}$ determination come from a normal population with the same variance as the other determinations (excluding the $\left.\left.28^{\text {th }}\right).\right]$ The $28^{\text {th }}$ and $39^{\text {th }}$ determinations were initially removed from the analysis because of the reversals in the time ordering of the resultant ratios, a physical impossibility. The statistical improbability of the F-ratio indicates that at least one of the sets of radium runs in each case was most probably the cause of the discrepancy.

\section{ESTIMATION MODELS}

The NBS half-life estimation procedure was to calculate the ratio of the temperature and pressure corrected net counting rate for krypton to the rate for radium similarly adjusted. Each ratio was adjusted for radium decay and a straight line fitted to the points defined by the logarithm of the ratios and the number of days since the start of the study to the day on which the ratio was determined. (The data available to us did not have a finer time lapse measurement than days.) This calculational procedure corresponds, in most respects, to what will be designated as Model 3. In the above notation Model 3 is

$$
\ln \rho_{3}=\alpha+B_{1} D
$$


The calculational formula for $\rho_{3}$, as given above, is the same as used by NBS in their calculation of the ratios except that it does not include an adjustment for radium decay. Our procedure was to fit the line to the logarithm of the ratios and to adjust the resulting slope as in Eq. (2).

Other models were investigated. Model 1 used the ratios defined by $\rho_{1}$ in a multiple linear regression fit of

$$
\ln \rho_{1}=\alpha+B_{1} D+B_{2} B+B_{3} E \text {. }
$$

The rationale for attempting to fit this model was that the ratio, $\rho_{1}$, is the ratio of the unadjusted counting times and the regression model provides a means of estimating the variability associated with the successive fitting of the regression parameters $\beta_{1}, \beta_{2}$, and $\beta_{3}$. However, Model 1 implies that the background correction is multiplicative. As is evident from the equations for $\rho_{2}$ and $\rho_{3}$; background is additive and so cannot be mathematically separated in the logarithmic transformation of the ratios. The coefficient matrix proved to be singular for this model, and so no solution was obtained. Model 1 will not be discussed further.

Model ? used the background corrected counting rates in the calculation of the ratios; $\rho_{2}$ but the temperature/pressure correction (a multiplicative factor) was used as a regression variable. Model 2 is:

$$
\ln p_{2}=\alpha+B_{1} D+B_{2} E
$$

As for Model 3, the estimate of the decay parameter $\left(\lambda_{K}\right)$ was the regression parameter $\left(B_{1}\right)$ adjusted for radium decay $\left(\lambda_{R}\right)$. 
Models 2 and 3 were applied to the entire data set (52 determinations, DET 39 being excluded), the subset characterized by use of the glass sample holder, and the subset using the plastic holder. The models were also run with the addition of a second "intercept" parameter for the glass subset. The effect on the fit of removing determinations suspected of being anomalous was also investigated.

The average of the half-lives calculated for 48 of the determinations was also used as an estimate of the half-life. Equation 3 and the equation preceeding it show that the decay parameter estimate is adjusted for radium decay. Each of the three ratio definitions was used to provide an average half-life estimation, but the first two ratios may be biased since they do not include temperature/pressure corrections and only the last two are background adjusted. For reasons discussed below, only the average half-life determination based on the second ratio $\left(\rho_{2}\right)$ will be discussed in detail.

The statistical uncertainty associated with the estimate of the halflife is an important quantity for this study. When the decay constant obtained by a regression model was used to estimate the half-life, "propagation of errors" (2) was used to estimate the associated variance. From Eq. (3),

$$
V\left(K_{1 / 2}\right)=(\ln 2)^{2} V\left(1 / \hat{\lambda}_{K}\right) \doteq(\ln 2)^{2} V\left(\hat{\lambda}_{K}\right) / \hat{\lambda}_{K}^{4},
$$

where $\doteq$ indicates an approximation through propagation of errors was used.

2. See H. H. Ku, "Notes on Propagation of Error Formulas", pp. 331-341 in Precision Measurement and Calibration, H. H. Ku, Ed., NBS Special Publication 300-Vol. 1, Feb. 1969. U.S. Gov't. Printing Office, Washington, D.C. 
From Eq. (2),

$$
\hat{\lambda}_{K}=\hat{\lambda}_{R}-b,
$$

and

$$
V\left(\hat{\lambda}_{K}\right)=V\left(\lambda_{R}\right)+V(b)
$$

where $b$ is the regression coefficient $\left(\hat{\beta}_{1}\right)$ associated with the mathematical variable $D$, i.e., days from start of study. The estimate of the half-life of Ra 226 used was $1620 \mathrm{yr}$. with a standard deviation of 2 years. ${ }^{(3)}$ This implies (through propagation of error formulas) that $V\left(\lambda_{R}\right)=2.091560 \times 10^{-18} /$ $(\text { day })^{2}$, and that $\lambda_{R}=1.171440 \times 10^{-6} /$ day. The $V(b)$ to be used is the variance of the estimate of $\beta_{1}$ calculated from the least squares fit of Model 2 or 3 . Combining the above formulas and calculations,

$$
V\left(k_{1 / 2}\right)=\left(\frac{\ln 2}{\hat{\lambda}_{K}^{2}}\right)^{2}\left[V(b)+2.091560 \times 10^{-18}\right] \text {, }
$$

and

$$
\operatorname{sd}\left(K_{1 / 2}\right)=\frac{\ln 2}{\hat{\lambda}_{K}^{2}} \operatorname{sd}\left(\hat{\lambda}_{K}\right)
$$

\section{RESULTS OF FITTING THE ESTIMATION MODELS}

The main objective of fitting a number of models was to determine which model was best, in the sense that it resulted in minimum variance for the half-life estimate. The model which best satisfied this criterion was Model 2, run with determinations 1 and 39 removed. The resulting equation was:

$$
\text { In } \rho_{2}=0.25229-\left(1.75934 \times 10^{-4}\right) \mathrm{D}+0.011316 \mathrm{E} \text {. }
$$

3. See the last section for a discussion of the impact on the analysis of various values for the half-life of radfumi-226. 
The estimate of $\lambda_{K}$ resulting from this model was $1.77106 \times 10^{-4}$, which produced a half-life estimate of 10.715 years with a standard deviation of 0.008 years. The 95 percent confidence limits on the estimate, based on the $t$ distribution with 48 degrees of freedom, were 10.699 to 10.732 years.

Some preiliminary analyses were required to arrive at Eq. (7). First, the data base had to be "firmed up". The problem of ratio reversals for determinations 28 and 39, referred to in the Data Editing Section was resolved by selecting the set of radium runs that removed the reversal and deleting the other set. For determination 28 the second set was used, and for 39 the first set was used. When Model 2 was run with all 53 determinations, the standard deviation of the estimated regression parameter, $b_{1}$, for days, $D$, was $2.5996 \times 10^{-7}$. The residual for determination 39 was more than 2.5 times the next largest residual. When determination 39 was removed completely, the $s d\left(b_{1}\right)$ was reduced to $1.4817 \times 10^{-7}$, a 43 percent reduction. On this run the residual for the first determination was the maximum, at -.00451 , and the next largest residual was -.00268 . The largest positive residual was .00240 . When $D E T 1$ was removed, the $s d\left(b_{1}\right)$ was reduced to $1.3447 \times 10^{-7}$, only a 9 percent reduction. This is not extremely persuasive evidence for removal of DET 1 , but other evidence, discussed later, makes it suspect. When model 2 was modified to include a dummy variable for the subset. of the data characterized by use of the glass sample holder, the estimate of the $G$ vs. $P$ parameter was not significantly different 
froll zero ( $t=1.08$ with $48 \mathrm{~d} . f$.$) when the 52$ observations, including DET 1, were used. But when DET I was removed, the parameter for the dummy variable was significantly different from zero $(t=1.92$ and $\left.P\left(t_{47}>1.92\right) \cong 0.03\right)$. This procedure is equivalent to testing the null hypothesis: a single regression equation $\left(\ln \rho_{3}=\alpha+\beta_{1} D+\beta_{2} E\right)$ is adequate to represent the data. Rejection of this hypothesis requires an explanation of what causes the differences between the fits for the glass and plastic data.

First, the fact that the above hypothesis was not rejected with DET 1 in the data set and the high negative residual for DET 1 leads to the conclusion that DET 1 was biased low. DET 1 is the day zero determination. Reference to Eq. (1) indicates that the logarithm of the day zero ratio is the intercept for the simple linear regression model. When the theory is extended to the three-parameter model 2, the intercept is the line in three-space above the $E$ axis where the regression plane intercepts the (In $p, E)$ plane. The estimate for $\ln \rho_{3,0}$ using the glass subset with DET 1 included was 0.36639 with a standard deviation of estimation of .0005730 . The actually observed logarithm of the ratio for DET 1 waS 0.36337 with a within determination standard deviation of 0.001049 (obtained via propagation of errors, and having approximately 4 d.f.). A test of the hypothesis that there is no statistical difference between the actually observed $\rho_{0}$ and the $\rho_{0}$ estimated from the model for the glass subset is available using the t-test. This test is highly significant $(|t|=4.50$ with. 43 d.f.). so that we can conclude that DET 1 produced a biased result. 
These considerations do not answer the question regarding why the glass and plastic data require different model parameters, but they do remove the confusion which may have resulted from leaving the biased status of DET 1 indeterminate.

The explanation of the difference between the results produced by the plastic and glass data sets is dependent upon a number of statistical tests. These are summarized in Table 1. The upper block of Table 1 gives the regression parameters for the various data sets. Note that $\mathrm{b}_{O P}$ is about 70 percent of $b_{O G}$ and that $b_{2 G}$ is about 57 percent of $b_{2 P}$, whereas $b_{1 P}$ is 99.6 percent of $b_{1 G}$. That is, there is little difference between the estimate of the regression parameter for days (D), but the plastic data produce an intercept which is 30 percent less than that for the glass data and the regression parameter for the temperature-pressure factor has a more extreme difference in the opposite direction. The statistical significance of these differences will be investigated below. The next block of statistics are the standard deviations associated with the estimates of the regression parameters. Note that the standard deviations of the parameters for the plastic data are 2.5 to 3.6 times those for the glass data despite the fact that the residual standard deviations are quite comparable. The next block of statistics provides estimates of the day zero ratios. These also appear quite comparable, the glass-plastic difference being 0.002 in the $1 n \rho_{0}$ units.

The summary statistics in the top part of Table 1 were used in the statistical tests summarized in the lower part of Table 1. The first test 
TABLE 1. Statistics For Model 2

\begin{tabular}{|c|c|c|c|c|}
\hline Statistic & $\begin{array}{c}\text { GLASS } \\
G \|=40 .\end{array}$ & $\begin{array}{r}\text { PLASTIC } \\
\text { P } N=11\end{array}$ & $\begin{array}{c}\text { ALL } \\
A N=51\end{array}$ & $\begin{array}{c}\therefore A L L \\
A-I \|=51\end{array}$ \\
\hline Intercept & .263642 & 185975 & .252290 & .251760 \\
\hline$I_{G} \quad 10^{3} \times b_{0}^{\prime}$ & & & & -1.004050 \\
\hline D. $\quad 10^{4} \times b_{1}^{\prime}$ & -1.762214 & -1.755395 & -1.759343 & -1.761482 \\
\hline $\mathrm{b}_{2}$ & .0102378 & .0178061 & .0113160 & .0115030 \\
\hline$s d\left(b_{0}\right)$ & .0181043 & .0446012 & .0175791 & .0171106 \\
\hline $10^{4} \times \mathrm{sd}\left(\mathrm{b}_{0}^{\prime}\right)$ & & & & 5.235555 \\
\hline $10^{7} \times s d\left(b_{1}\right)$ & 1.748069 & 6.295303 & 1.344667 & 1.719516 \\
\hline $10^{3} \times s d\left(b_{2}\right)$ & 1.797103 & 4.497314 & 1.745034 & 1.701103 \\
\hline $10^{3} \times$ Resid. sd & 1.136506 & 1.134516 & 1.195931 & 1.163906 \\
\hline$b_{2} \bar{E}$ & 102966 & .178645 & .113750 & .115630 \\
\hline$\widehat{\ln \rho_{0}}$ & .366608 & .364620 & .366048 & .365985 \\
\hline$\hat{\rho}_{0}$ & 1.442833 & 1.439967 & 1.442025 & 1.441933 \\
\hline $\mathrm{K}_{1 / 2}$ & 10.6979 & 10.7392 & 10.7153 & 10.7023 \\
\hline sd $\left(k_{1 / 2}\right)$ & .01054 & .03826 & .00814 & .01038 \\
\hline
\end{tabular}

Null Hypothes is

1. $G$ and $P$, have the same residual variance

2. Residuals for $G$ $\& P$ are from the same distribution

3: ${ }^{B_{O G}}=\beta_{O P}$

4. $B_{1 G}=B_{1 P}$

$t=.07766 / .02496=3.11$

$t=6.819 \times 10^{-7} / 6.384 \times 10^{-7}=1.07$

5. $B_{2 G}=B_{2 P}$

$t=-.007 .568 / .004740=-7.60$

$t=.00199 / .00168=1.18$
$<.005$

Probability NS $(.50)$

.1141

HS $(.28)$

.1168

HS $(.24)$ 
compares the residual variances for Model 2 applied to the glass and plastic data separately. The F-ratio is near unity indicating that the underlying variance structure is the same for the two data sets once the variability due to days and $T / P$ has been removed. This conclusion does not imply that a single fit of the combined data sets is appropriate. In fact, a MannWhitney U-Test done on the residuals from the fit of Model 2 to the combined data set $(A, N=51)$ approached significance. (The test statistic $z_{U}$ is asymptotically normally distributed.) Acceptance of hypothesis 2 is questionable.

Since the fit of Model 2 is so good, accounting for almost 100 percent of the variability, the non-significant (INS) result of the test of hypothesis 1 implies that the residual standard deviation is a good characterization of the experimental variability; i.e., the uncertainty associated with the logarithm of a determination ratio. This test also eliminates heterogeneity between the glass and plastic experimental variances from consideration as a factor contributing to the significant difference between the results of the two data sets. The fact that the 11 residuals for the plastic data set are not uniformly distributed among the 40 residuals for the glass set, ( 3 were below and 8 above the median residual of the combined data set and the U-test approached significance) implies that combining the glass and plastic data sets without an adjustment for the difference could bias the half-life estimation. The predominantly positive residuals for plastic indicate that the combined fit underestimates the In $\rho_{2 i}$ for the plastic holder data. 
The third test indicates that the intercept $\left(\beta_{0}\right)$ for glass is different from, i.e., significantly larger than, the intercept for the plastic data set. Thus, the intercept is definitely a contributing factor to difference between the results of the application of model 2 to the two data sets. The fourth test indicates that a single regression parameter for days, $\beta_{1}$, can be used. This is encouraging since it is upon $\beta_{1}$ that the hal $f-1$ ife estimate will be based. The test of the fifth hypothesis produced a twotailed probability of 0.1168 . (A11 tests are against the two-sided alternative of non-equality). Although 0.1168 is slightly greater than the 0.1 level usually used as the upper limit for rejecting hypothesis, it is close enough to make the acceptance of hypothes is 5 suspect. The difference between the parameters associated with the T/P factor is large enough to contribute to the significant difference observed in the application of model 2 to the $G$ and $P$ data sets.

The overall conclusion to be drawn from these tests is that the best estimate of the regression parameter for days will be obtained by combining the two data sets and using the resulting estimate of $\beta_{1}$ to estimate the half-life. Fortuitously, in a relative sense, the plastic data underestimate the intercept and overestimate the parameter for the T/P factor so that the estimates of in $\rho_{0}$ at the points for day zero and $\bar{E}_{G}$ or $\bar{E}_{p}$ are not significantly different. The results indicate that the lines for the two data sets, adjusted to the average T/P factor, have the same intercept and are parallel. The significant difference between the two data sets is real, but it has no real effect on the half-life estimation. Consequently, model 2 with determinations 1 and 39 removed provides the best estimate of $\beta_{1}$. 
The second best model was a modified model 3 , namely

$$
\ln \rho_{3^{\prime}}=0.25273-\left(1.75943^{\circ} \times 10^{-4}\right) D+0.011274 E \text {. }
$$

This will be referred to as Model 3E. By this time the reader should be familiar enough with the order of magnitude of the variability being dealt with to recognize from Table 2 that the estimated parameters of Eq. 8 are within a standard deviation of those for Eq. 7 (model 2). In particular, $b_{12}-b_{13 E}=9.1 \times 10^{-9}$ and $s d\left(b_{12}-b_{13 E}\right)=1.936 \times 10^{-7}$, so that a t-test on the difference between the regression parameters for days for models 2 and model $3 E$ would be less than unity and consequently be non-significant. The difference in half-life estimates is only 0.0006 years, well within a standard deviation. In fact, the differences between model 2 and mode $3 E$ are so minute that they are approximately what would be expected from rounding error, which could have an effect on the 5th or 6th decimal place of the $\rho$ values. (The original data were recorded to six significant digits.)

Table 2 also includes a column for model 3, which was:

$$
\text { In } \rho_{3}=0.366273-\left(1.760256 \times 10^{-4}\right) \mathrm{D} \text {. }
$$

An $F$ test of the null hypothesis that the addition of the $T / P(E)$ variable does not improve the fit produced a value of 38.22 . The probability of obtaining a value this large is less than 0.0001 . This significant $F$ test indicates that the addition of the T/P variable to model 3 produced a significant improvement in the fit of the data. This was not expected since the calculation of $\rho_{3}$ included a correction for T/P. Theoretically, if the correction for $T / P$ in 


\section{Table 2}

Model 2 Compared to Model $3 \mathrm{E}$ and Model 3

\begin{tabular}{|c|c|c|c|}
\hline & $N=51$ & & \\
\hline Statistic & Model 2 & Model 3E & Model 3 \\
\hline$b_{0}$ & .252290 & .252731 & .366273 \\
\hline $10^{4} \times b_{1}$ & -1.759343 & -1.759434 & -1.760256 \\
\hline$b_{2}$ & .0113760 & .0112738 & \\
\hline$s d\left(b_{0}\right)$ & .0175791 & .0183694 & .000540 \\
\hline $10^{7} \mathrm{sd}\left(\mathrm{b}_{1}\right)$ & 1.344667 & 1.405135 & 1.855573 \\
\hline $10^{3} \mathrm{sd}\left(\mathrm{b}_{2}\right)$ & 1.745034 & 1.823507 & \\
\hline $10^{3} \times$ sd(Resid.) & 1.195931 & 1.249711 & 1.657764 \\
\hline$k_{1 / 2}$ & 10.7153 & 10.7147 & 10.7097 \\
\hline $\operatorname{sd}\left(K_{1 / 2}\right)$ & .00814 & .00850 & .01215 \\
\hline $\mathrm{b}_{2} \mathrm{E}$ & .113685 & . 113261 & - \\
\hline $\ln \hat{\rho}_{0}$ & .365974 & .365992 & .366273 \\
\hline$\hat{\rho}_{0}$ & 1.441919 & 1.441943 & 1.442349 \\
\hline 95\%. $\mathrm{CL}$ on $\mathrm{K}_{1 / 2}$ & & & \\
\hline Lự & 10.0950 & & \\
\hline Upper & 10.7316 & 10.7318 & 10.7341 \\
\hline
\end{tabular}


the calculation of $\rho_{3}$ were adequate, one would expect that the average $T / P$ levels for the determinations would not be a significant variable in the linear regression fit. Apparently the T/P "correction" accounts only for within determination temperature and pressure differentials. The. T/P variable used in Models 2 and $3 E$ is the average $\left(\bar{E}_{j}\right)$ of the $T / P$ determinations $\left(E_{v i j}\right)$ within each determination. The fact that $\bar{E}_{i}$ is a significant regression variable indicates that the between determination differences in $T / P$ have an effect that is not accounted for by the corrections for $T / P$ which were made. Further, if the within determination correction for $T / P$ had any effect at all, one would expect Model 2 to have a regression parameter different from those for Model $3 E$, since model 2 uses $\rho_{2}$ which has no correction for $T / P$. In fact, a t-test on the differences between the calculated ratios $\left(\rho_{2 i}-\rho_{3 i}, i=2, \ldots, 38,40, \ldots, 53\right)$ resulted in the low value 0.151 . This non-significant result indicates that the T/P "correction" used for $\rho_{3}$ makes no appreciable difference in the results.

The conclusion to be drawn from these comparisons of Models 2, 3E and 3 and the T/P $\left(\bar{E}_{j}\right)$ factor is that the within determination $T / P$ adjustment was not needed, but that a between determination correction is required. The regression parameter estimator $b_{2}=.011316$ provides the weight to be given to the average temperature/pressure ratio $\left(\bar{E}_{i}\right)$ for each determination.

In summary of the model fitting effort it was found that:

- The best precision of estimation was given by Mode1 2,

$$
\ln \rho_{2}=0.25229-\left(1.75934 \times 10^{-4}\right) \mathrm{D}+0.011316 \mathrm{E} \text {. }
$$


- The estimate of the half-life of krypton-85 resulting from this model was 10.715 years.

- The standard deviation of the estimate was 0.003 years, equivalent to about 3 days or to a relative (to the estimate) standard deviation of 0.076 percent.

- Confidence limits on the estimated half-life at the 95 percent level were $(10.699,10.732)$.

- There is a significant difference between the results of applying Model 2 to the data set characterized by the use of the glass sample holder and the set using the plastic holder, but this difference affects only the intercept and $T / P$ parameter, not the parameter associated with days upon which the half-life estimate was based.

- A between determination adjustment for $T / P$ is more important than a within determination correction.

\section{AVERAGE HALF-LIFE ESTIMATE}

The basic objective of NBS's experiment was to determine the half-life of $\mathrm{k}, \mathrm{r}-85$, or, equivalently, lhe decay rate. The decay rate is the number of atoms which disintegrate to another nuclear form per unit time. As such, the decay rate can be estimated by the slope associated with the exponential decay equation. It is well known ${ }^{(4)}$ that the least squares estimate of the

4. See, e.g., F. A. Graybill, An Introduction to Linear Statistical Models, McGraw-Hi11, 1961, p. 115, Theorem 6.2. It was assumed that the conditions of this theorem were not violated by the use of the random (as opposed to mathematical) variable $\bar{E}_{i}$. 
slope is the minimum variance unbiased estimate of the slope when the measurement errors are statistically uncorrelated and have the same variance., Since these conditions appear to be met, one would not expect the estimate based on the average half-life to be better, in the sense of having a smaller variance. But it is informative to go through the calculation to dissuade others estimating half-lives who could use the regression method but expect to try the average method. (5)

The conclusions of the regression analysis included the fact that there was no statistically significant difference between the determination ratios whether calculated by the formula for $\rho_{2}$ or the formula for $\rho_{3}$ and that the $T / P$ correction used had no significant effect on the results. These conclusions provide the basis for using the individual half-life determinations based on $\mathrm{P}_{2}$ in the average half-life method of estimating the half-life. Also, the conclusion that the first ratio determination was biased low suggested that a better estimate of $\mathrm{K}_{1 / 2}$ would be obtained if the Model 2 estimate of the day zero ratio, $\hat{\rho}_{0}$, were used.

The average half-life method of estimating the half-7ife of krypton-85 produced an average of 10.7142 based on the $\rho_{2}$ for 48 determinations, (determinations 1,2 and 3,28 and 39 were not included). The standard

5. e.g., R. K. Wanless and H. G. Thode in the Canadian Journal of Physics, Vo1. 31, 1953, reported a standard deviation of $0.18 \mathrm{yr}$. on their estimate of $\mathrm{K}_{1 / 2}$ of 10.27 years. They averaged the determinations from two different ratio determinations and took the average of the 7 resulting averages and calculated the sd based on the 7 averages. The averages for the two columns in their Table II of ratio deterninations are statisticaliy different, and so should not have been averaged together. The regression method could have been applied to their basic $\mathrm{Kr}^{85} / \mathrm{Kr}^{84}$ and $\mathrm{k} 85 / \mathrm{Kr} 86$ ratios. The resulting uncertainty on their estimate would then have been more meaningfu? . 
deviation of the 48 determinations was 0.0407 years, so that the standard deviation of the average of the determinations was 0.00587 (or 2.1 days). This precision is $28 \%$ better than the best $l$ inear regression model. However, this standard deviation of the average half-life does not reflect the total uncertainty due to random error which should be considered when characterizing the precision of the estimate. At each determination (i), $k_{1 / 2}$ was. estimated by Eq. (3) which, with $i$ and the calculation of $\hat{\lambda}_{K}$ explicit, is

$$
K_{1 / 2 i}=\ln 2\left[\left(\ln \rho_{i}-\ln \rho_{0}\right) / D_{i}+\lambda_{R}\right]^{-1} .
$$

This equation uses the quantities $\ln \rho_{0}$ and $\lambda_{R}$ for each determination. The "between determination" variability estimated by the standard deviation of the determinations does not include the variability due to the "corrections" for $\ln \rho_{0}$ and $\lambda_{R}$ :

The propagation of errors required to obtain a realistic estimate of the uncertainty on the average half-life involves some straightforward algebra. The chain of equations relating the basic measured quantities which "carry" their associated variability, are as follows.

$$
\begin{aligned}
& \bar{K}_{1 / 2}=\frac{1}{48} \sum_{i=1}^{48} k_{1 / 2, i} \\
& k_{1 / 2, i}=-\ln 2 / \hat{\lambda}_{K i} \\
& \hat{\lambda}_{K i}=\left(\ln \rho_{2, i}-\ln \rho_{2,0}\right) / D i-\lambda_{R}
\end{aligned}
$$


The required propagation of error formulas are:

$$
\begin{aligned}
& \dot{V}\left(\bar{K}_{1 / 2}\right)=\frac{1}{48} \sum_{i=1}^{48} V\left(K_{1 / 2, i}\right)+\frac{1}{47(48)} \sum_{i \neq j} \operatorname{cov}\left(K_{1 / 2, i}, K_{1 / 2, j}\right) \\
& V\left(K_{1 / 2, i}\right) \doteq\left(\frac{\ln 2}{\hat{\lambda}_{K}^{2}}\right)^{2} V\left(\hat{\lambda}_{K i}\right) \\
& V\left(\hat{\lambda}_{K i}\right)=\frac{1}{D_{i}^{2}} V\left(\ln \rho_{2, i}\right)+\frac{1}{D_{i}^{2}} V\left(\ln \rho_{2,0}\right)+V\left(\lambda_{R}\right)
\end{aligned}
$$

The covariance (cov) terms in Eq. (13) are zero since each half-life determination is independent of the others. There may have existed some dependencies in the measurement errors from determination-to-determination, but they are included in the variance estimator used. The variances required are given by Eq. (15). $V\left(\ln \rho_{2, j}\right)$ was estimated by the residual variance from the fit of Model 2 as $s_{r}{ }^{2}=1.430250 \times 10^{-6}$. Model 2 also provided the $v\left(\ln \rho_{2,0}\right)$.

$$
V\left(1 \hat{n} \rho_{0}\right)=s_{r}^{2}\left[1+x_{0}^{\top} c x_{0}\right]=1.583355 \times 10^{-6}
$$

where $C$ is the inverse of the variance-covariance matrix for Model 2 and $X_{0}{ }^{\top}$ is the vector $(1,0, \bar{E})$ with $\bar{E}=10.0521$, the overall average $T / P$ adjustment. Finally,

$$
V\left(\lambda_{R}\right) \doteq\left(\frac{\ln 2}{(1620)^{2}}\right)^{2}\left(\frac{4}{365.25}\right)^{2}=2.091577 \times 10^{-18} /(\text { day })^{2}
$$

Then

$$
V\left(\hat{\lambda}_{K i}\right)=\frac{1}{D_{i}^{2}}\left(1.430250 \times 10^{-6}+1.583355 \times 10^{-6}\right)+2.092 \times 10^{-18} \text {. }
$$


and

$$
\begin{aligned}
v\left(K_{1 / 2, i}\right) & =\left(\frac{\ln 2}{\left(1.771237 \times 10^{-4}\right)^{2}}\right)^{2} v\left(\hat{\lambda}_{K i}\right) \\
V\left(\bar{K}_{1 / 2}\right) & =\left(1.016957 \times 10^{13}\right)\left(\frac{3.013605 \times 10^{-6}}{71,842.69}+2.092 \times 10^{-18}\right) \\
& =426.586
\end{aligned}
$$

and

$$
\operatorname{sd}\left(\bar{K}_{1 / 2}\right)=20.65 \text { days }=.0565 \text { years } .
$$

The conclusion is that the necessary inclusion of the within determination random variability of the $\ln \rho_{2, i}$ and accounting for the variability due to the repeated use of $\ln \rho_{2,0}$ raises the uncertainty on the average half-life estimate by about a factor of 10 , from $5.87 \times 10^{-3}$ to $5.65 \times 10^{-2}$ years. The total standard deviation of the average half-life estimate is thus 6.7 times the standard deviation of the regression estimate $\left(8.14 \times 10^{-3}\right.$ years).

NOTE ON CORRECTION FOR RADIUM DECAY

A summary of the results of determinations of the half-1ife of radium-226 is given in E. K. Hyde, I. Perlman, and G. T. Seaborg, The Nuclear Properties of the Heavy Elements: Vol. II, Detailed Radioactivity Properties, Prentice Hal1, 1964; pp. 449-451. The value used in the present report, $1620 \pm 2$ years, was adequate for making the radium decay correction. When the higher value of $1622 \pm 13$, accepted for use by Hyde et al, was used, the $k_{1 / 2}$ estimate was 10.71534 years, compared to 10.71526 for the 1620 year value, and $\mathrm{sd}\left(\mathrm{K}_{1 / 2}\right)$ obtained with a standard deviation of 13 was 0.0082 compared to 0.0081 . Reference to Kohmian, Ames, and Sedlet's paper (Paper 22.60, "The Specific 
Activity of Radium", in The Transuranium Elements, Part II, edited by G. T. Seaborg et al., McGraw-Hill, 1949) revealed that \pm 13 referred to a "probable error" based on a standard deviation of weighted (somewhat subjectively) observations and weighted averages with a systematic error component of 0.5 percent combined into the \pm value in an unreported manner. Thus, the \pm 13 is not a simple standard deviation and so cannot be validly compared with the \pm 2 , which reflects, to the nearest year, a relative standard deviation of 0.1 percent of 1620 years. So much has been done to arrive at the \pm 13 figure that recovery and verification of the underlying standard deviation would require a reanalysis of the data given by Kohman et al.

The low value obtained by Martin and Tuck in 1959 after they "critically evaluated all published information" was, as reported by Hyde et al., 1602 years. Use of this value produced a $\mathrm{K}_{1 / 2}$ of 10.71446 years, a reduction of less than 0.01 percent. The lowest value discussed by Hyde et al., 1577 years gave a $k_{1 / 2}$ of 10.71332 years, a reduction of less than 0.02 percent from the value of 10.71526 obtained with the 1620 year value. The conclusion is that any value in the broad range of usually used values for the half-life of radium-226. would give closely comparable results when used to correct for radium decay. The results of the present report were not adversely affected by use of $1620 \pm 2$ as the half-life of radium.

A pessimistic estimate of the uncertainty on the half-life of Ra-226 is available from Table 6.6 of Hyde et al. Excluding the two lowest specific alpha activity values (2.9 and 2.98), the calculated standard deviation relative. to the average value of $3.575 \times 10^{10} \alpha$-particle per second per gram was 4.4 percent. Such a relative standard deviation indicates that the standard deviation of the determinations to date is about 70 years. Even when the next three lowest determinations $(3.15,3.22$ and 3.33$)$ and the highest determination 
(3.88) were removed the standard deviation (0.1044) was 2.9 percent of the average value, 3.600. Applying this to the half-life estimate of 1620 , the standard deviation was 47 years which, propagated into the uncertainty on $\mathrm{K}_{1 / 2}$ gave a value of 0.00839 years compared to the original value, based on \pm 2 , of 0.00814 . Even this extreme case has little effect on the final resuits. 
APPENDIX

LISTING AND SUMMARIES OF DATA 


\section{CONTENTS}

PAGE

DESCRIPTION OF TABLES A-1

COMPUTATION SHEETS FOR DETERMINATIONS $1,2,3$ A-5

TABLE

1 LISTING OF KRYPTON HALF-LIFE DETERMINATION DATA

2 LISTING OF DATA SUIMMARY FOR REGRESSION ANALYSIS

3 INDIVIDUAL HALF-LIFE DETERMINATIONS WITH SUMMARY, STATISTICS

4 WITHIN RUN AVERAGES, STANDARD DEVIATIONS AND COEFFICIENTS OF VARIATION

5 DETERMINATION AVERAGE COUNTING TIME, T/P FACTOR, BETWEEN RA RUN SD, WEIGHT, AND SD OF T/P FACTORS WITH POOLED STANDARD DEVIATIONS 


\section{DESCRIPTION OF TABLES}

The Tables are largely self-explanatory but a few comments on coding and calculations will be given for each.

\section{TABLE 1}

This basic data for the experiment was key punched from copies of NBS's computation sheets. The first column, headed DET is the determination identification number. Copies of the data sheets for the first three determinations, which used a voltmeter rather than a capacitor in the $4 \pi y$ chamber set up, are given separately below since the records did not conveniently fit the card format used for the rest of the data. The second column, headed $E$, gives the coded experimental run sequence. The background, radium and krypton runs were done in different orders for different determinations and coded as follows.

\begin{tabular}{|c|c|c|}
\hline Run Sequence & Code & Number of Instances \\
\hline$B-R-K-R-B$ & ] & 41 (ATso DET's $28 \& 39$ ) \\
\hline$R-B-K-B-R$ & 2 & 5 \\
\hline$R-B-K-K-R-B$ & 3 & ] (DET 1) \\
\hline$R-K-R-B$ & 4 & 1 (DET 2) \\
\hline$R-B-K-R-B$ & 5 & 2 \\
\hline$B-R-B-K-B-R-B$ & 6 & 1 (DET 44) \\
\hline
\end{tabular}

The $E$ code was not used in the analysis. This is not the same as the $E$ (for environment) used as the name of the T/P ratio.

The DAY column gives the days from the start of the study. The column headed $y$ has $]$ designating background, 2 for radium, and 3 for krypton 
sample runs. The next column, J, gives the ID for the first (1) or second (2) set of runs on a $B$ or $R$ sample. For $K$ runs $(V=3) J$ merely designates the first.or second card of the single set of runs. [Only DET 1 had the $K$ runs separated.] The four separate background runs for DET 44 were handled as two sets of duplicate runs.

The column headed $C$ contains the codes for the background count adjustment factor used to put the background counting time on the same basis as the sample runs. The codes were as follows:

\begin{tabular}{ccc} 
Count Factor & & Code \\
\cline { 1 - 1 } .001 & & 7 \\
.002 & & 2 \\
.003 & & 3 \\
.004 & & 4 \\
.005 & & 5 \\
.01 & & 6 \\
$i 02$ & & 7 \\
$i / 3$ & 8 \\
.1 & & 9 \\
$i .03$ & & 10 \\
$i / 300$ & 11 \\
$1 / 30$ & & 12
\end{tabular}

The columns headed $k=1$ thru $k=6$ give the observed counting times for each set of replicate runs on each sample. The last two columns give the average temperature and pressure observed during, or temporatiy nearest, the set of runs.

The determinations using the plastic sample holder have a $P$ preceeding the DET ID. The last two determinations listed are the determinations with calculated ratios which were anomalous because they did not rank in temporal 
order. They have the ID's used in the initial coding and so have duplicates in the sequence of ID's for the DETS used. The ratio reversa? was corrected by removal of the first set of radium runs for DET 28 and the residual from the least squares fit was not unusually large so DET 28 , with the single set of radium runs, was used in the final analysis. DET 1 was removed so that the final analysis was based on 51 determinations. [The last two lines are the result of a printer jam on a trailer card and do not reflect any dissatisfaction with the data.]

\section{TABLE 2}

A computer code was written to calculate and punch the summary variables listed in Table 2 from the basic data of Table 1. The calculational formulas for the variables are given in the text. [Add the subscript $i$ and let $R=\rho$.$] DETs 2$ and 3 were hand calculated. The first DET 28; with OUT 28 at the end, is the determination based on the single usable set of radium runs.

\section{TABLE 3}

This table, and the next two, was generated by the same computer code as above. It was based on the data from 48 determinations, (DETs $1-3$ and anomalous 28 and 39 were removed). The first 7 columns contain the punched data tabulated in Table 2. The last three columns contain the individual half-life estimates, in years, based on $\rho_{1}, \rho_{2}$ and $\rho_{3}$, respectively. 
The last three rows are the summary statistics for the columns of data to which they are related by the angled lines. The column average, standard deviation and coefficient of variation as a percentage (100 sd/AVE) are given.

TABLE 4

The title describes the contents of this table except for the fact that $N$ is the number of replicate runs in each set of runs and that RUN 2 for the KRYPTON columns merely contains a copy of RUN 1.

\section{TABLE 5}

This table, in columns 3,4 and 5, gives the averages, over all replicates and runs of the counting times for each sample determination. The TP FACTOR column was calculated according to the formula for $E_{i}$ in the text. The R1-R2 SD solumn contains the between radium determination standard deviations. The DET WT column was not used in the analyses reported. The values were calculated by dividing the AVE KR counting time by the nominal half-life value of 10.72 years. The weighted regression done using these determination weights in an attempt to account for a potential differential effect due to the different counting time durations did not improve the fit. The last column contains the standard deviation of the 5 or 6 temperature/pressure ratios used to calculate the TP FACTOR $\left(E_{i}\right)$. The last line of the table contains the pooled standard deviations and associated degrees of freedom for within and between determination radium runs, and within determination temperature/pressure. 
A-5

COMPUTATION SHEETS

FOR

DETERMINATIONS $1,2,3$ 


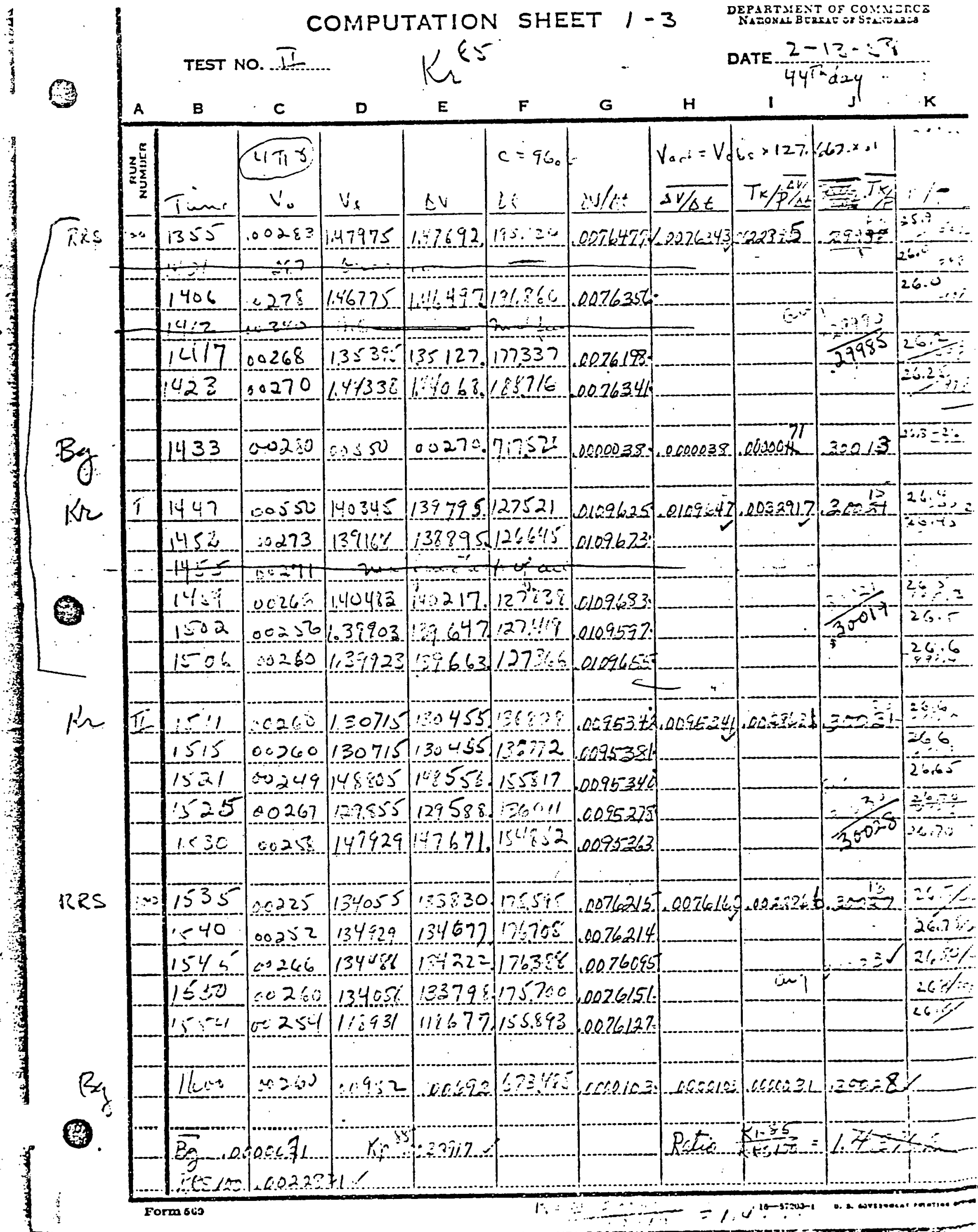




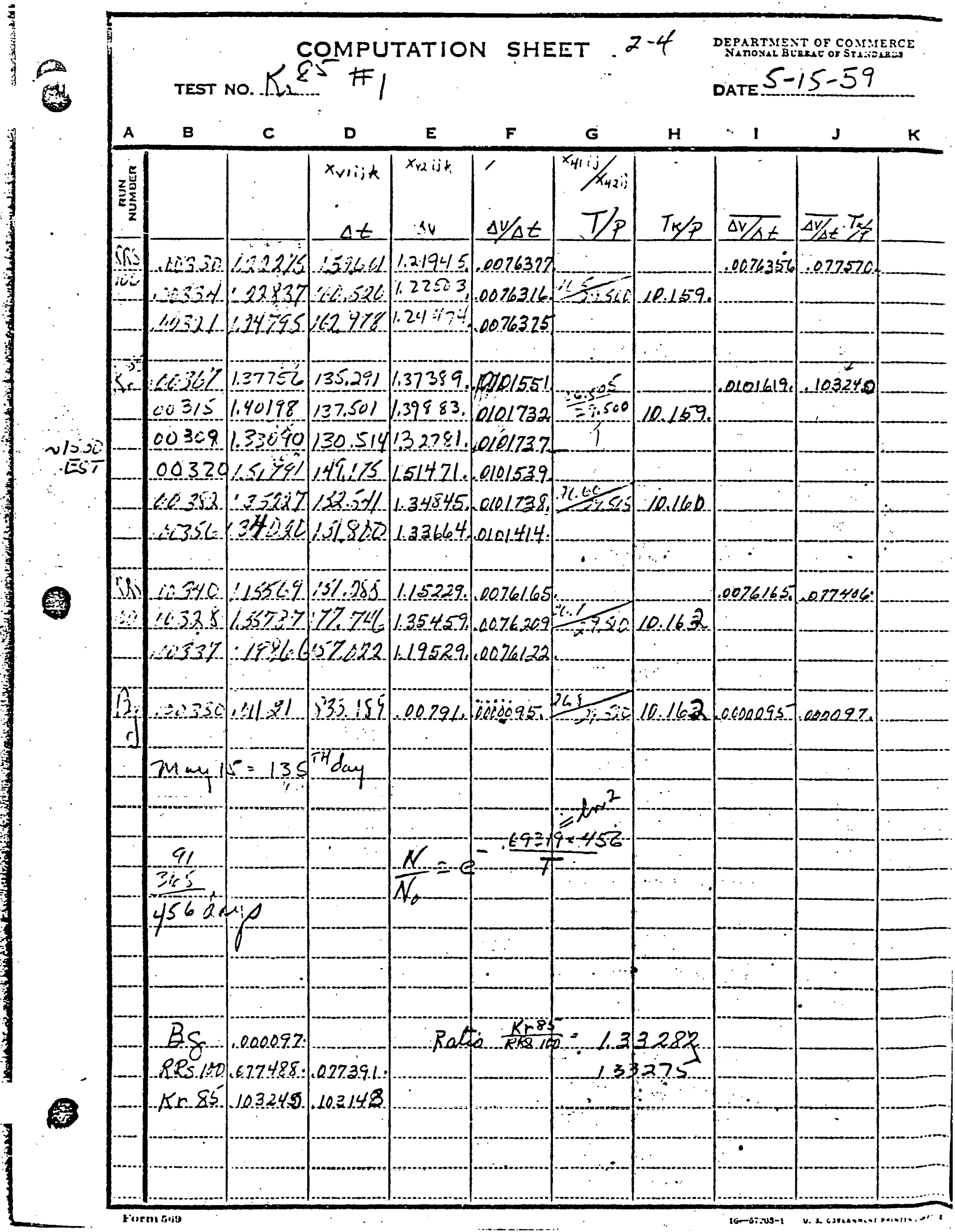


COMPUTATION SHEET

TEST NO.

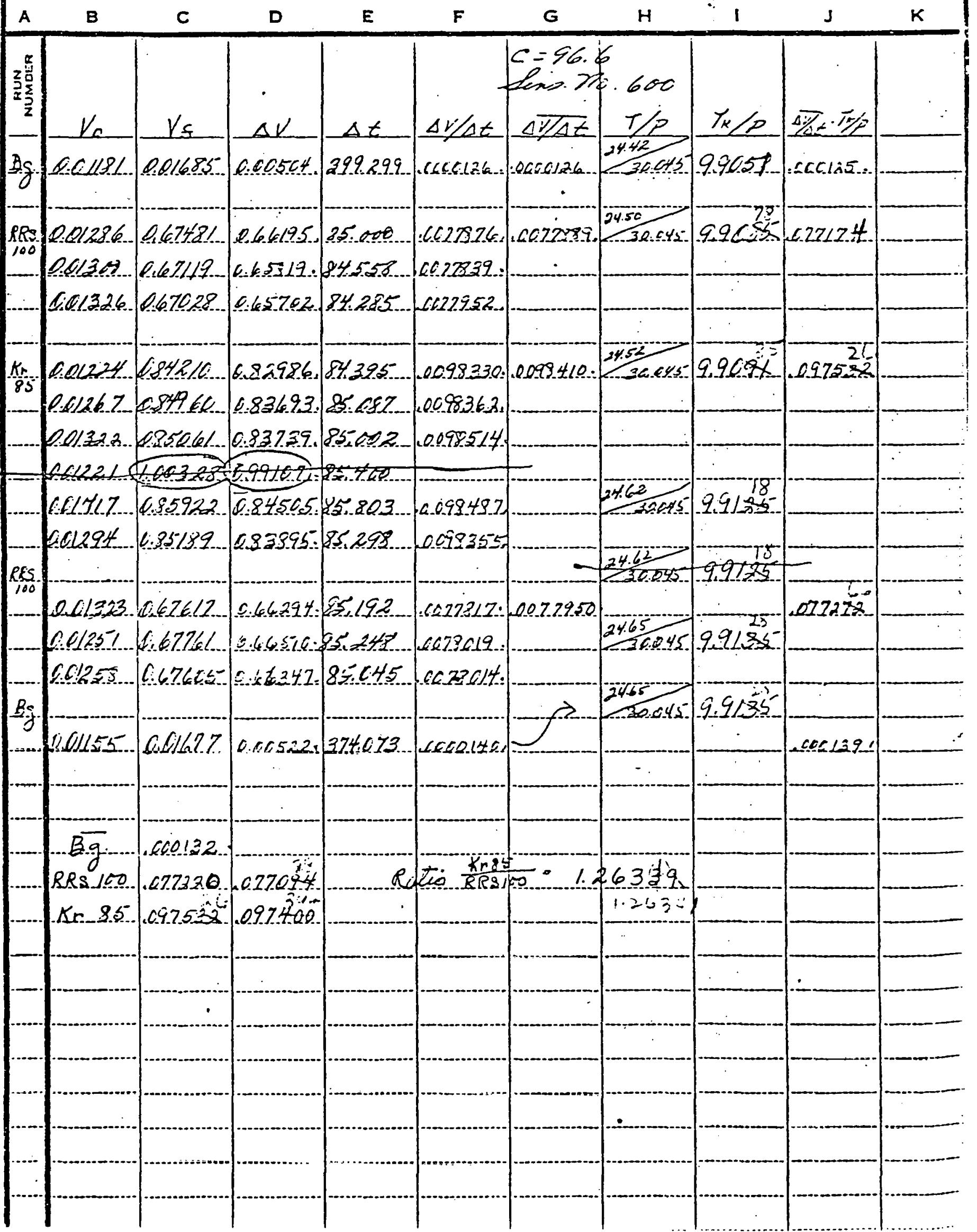

DEPARTMENT OF COMMEPCE NATIONAL BeBRA OI SILIOABDS

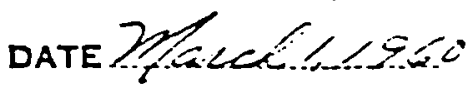


TABLE 1

1. ICTING OR YRYOION IMLT-LFEF OFTFRMINATION DATA

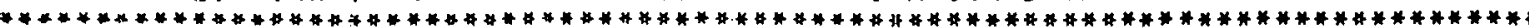
$X(v, I, J, K)$

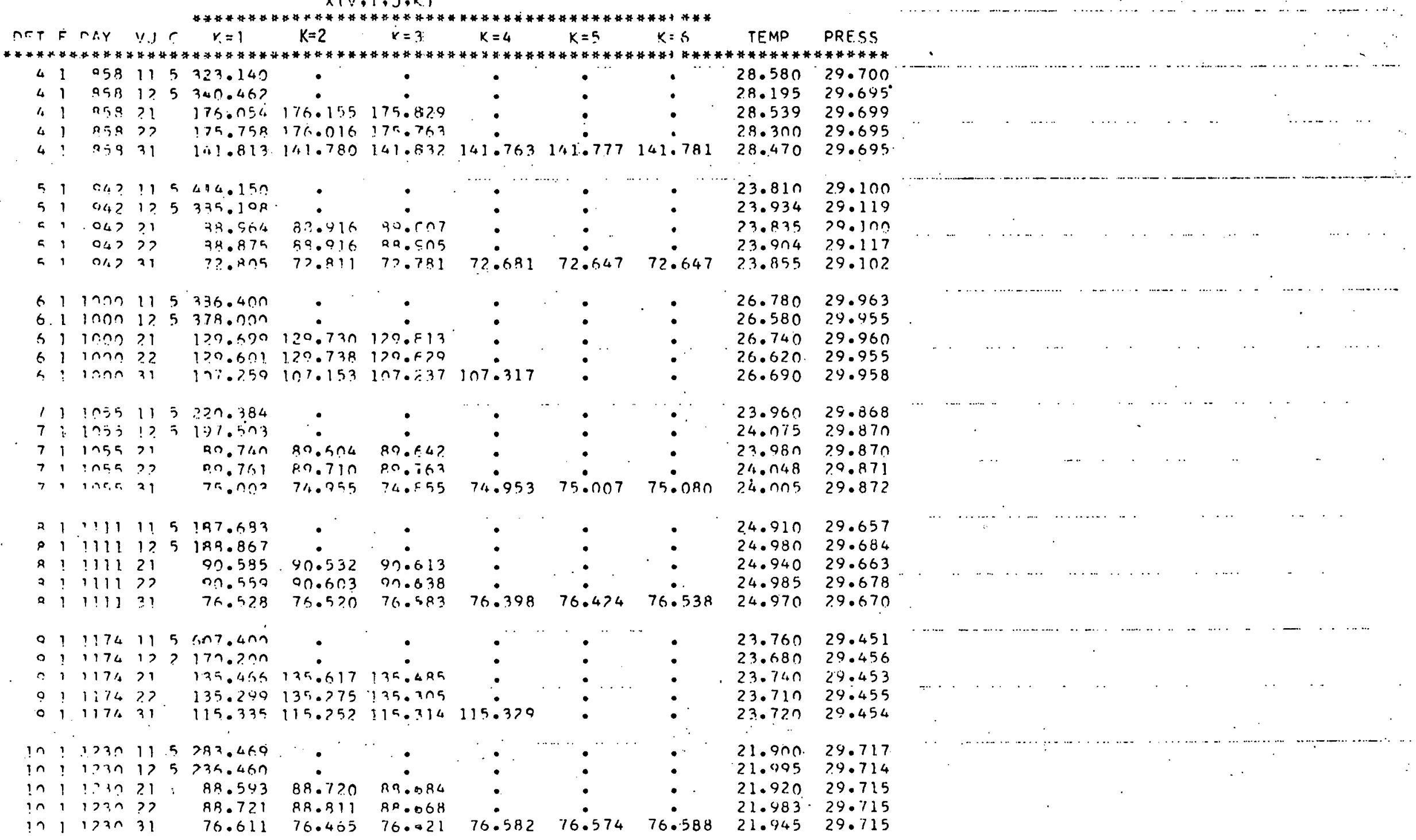




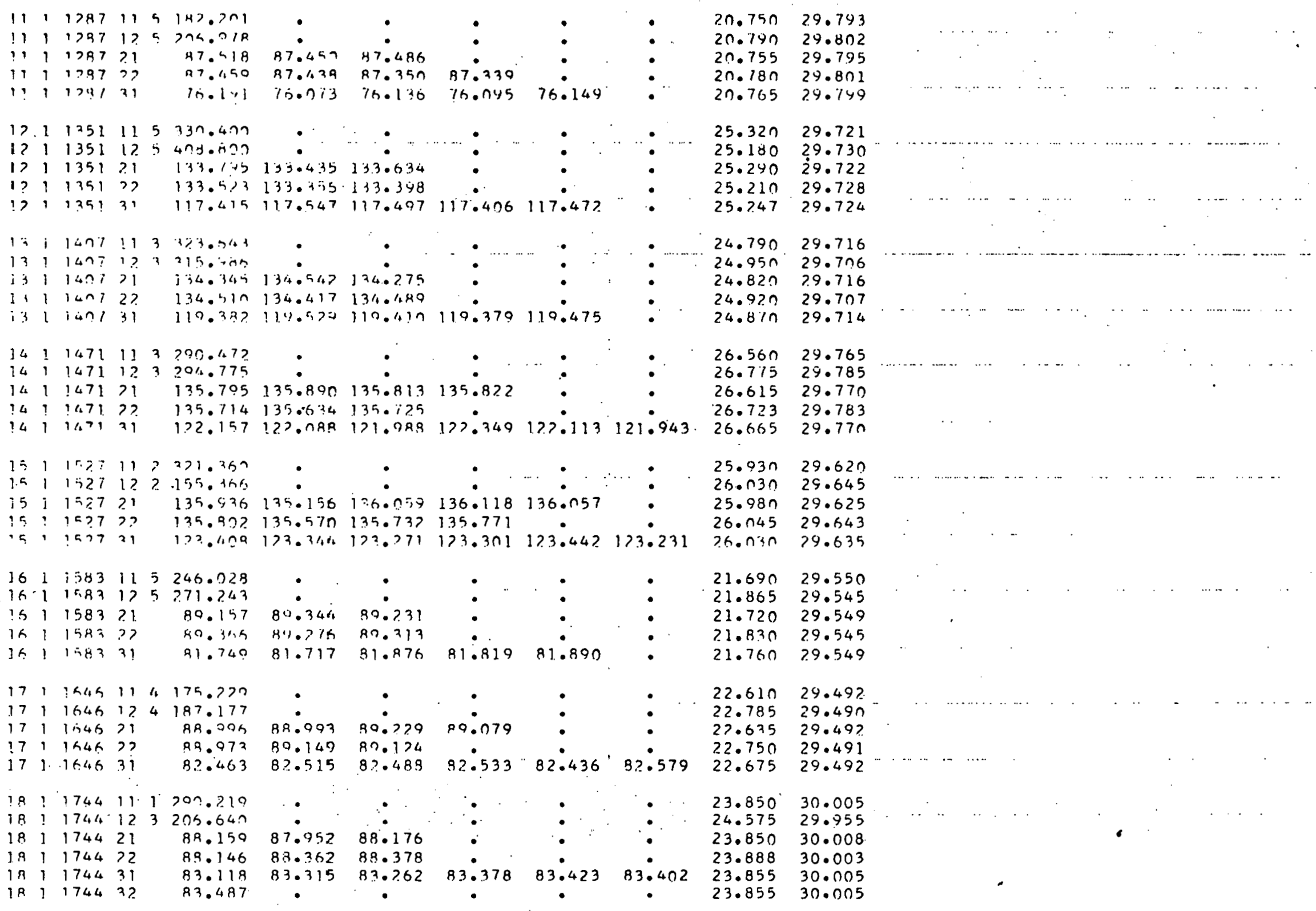




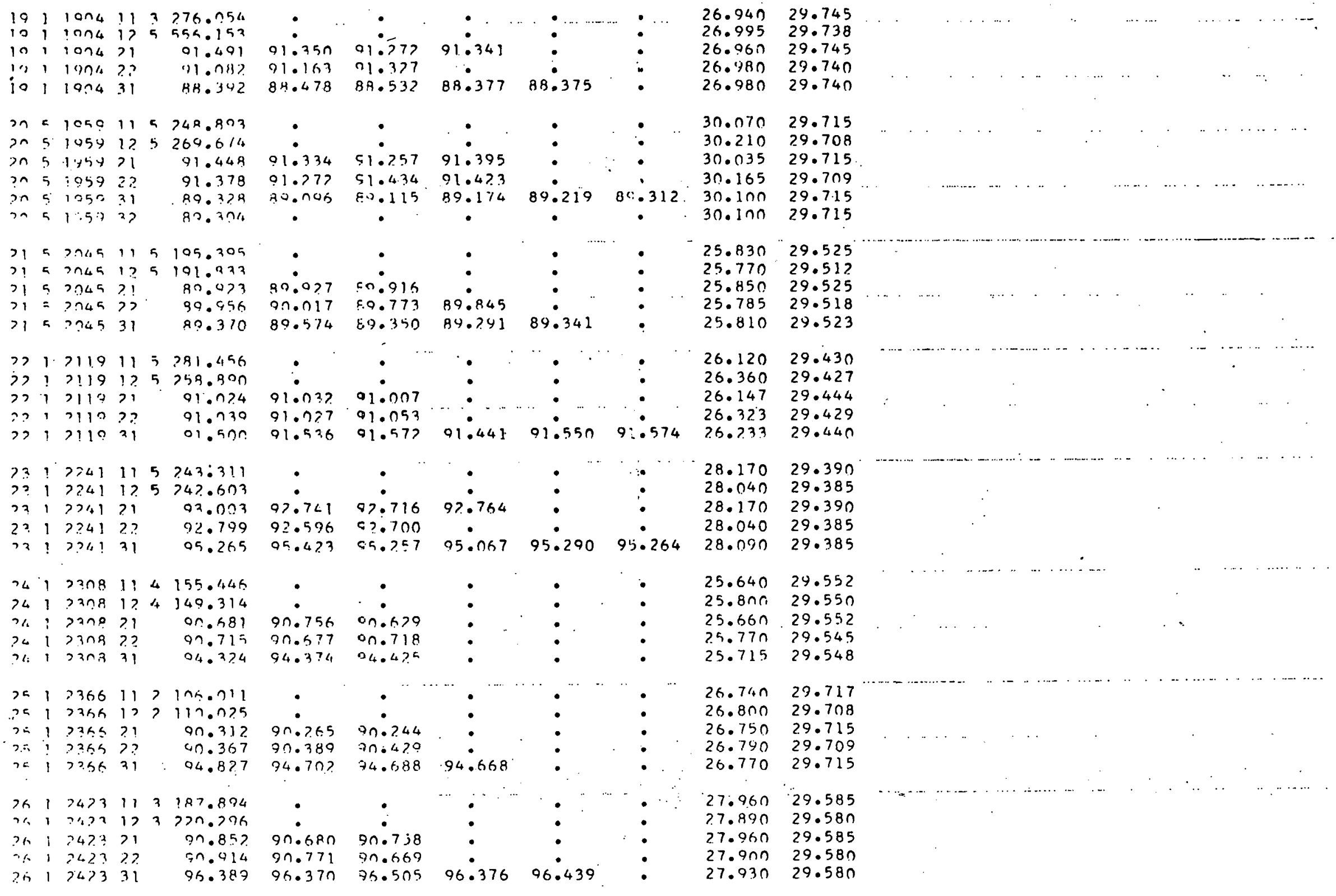




\begin{tabular}{|c|c|c|c|c|c|c|c|c|c|c|c|c|}
\hline 7 & 1 & O & $!$ & $?$ & "A.AOA & & & & 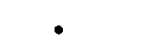 & 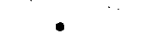 & - $n 4 n$ & 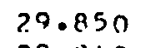 \\
\hline$\%$ & 1 & $3(480)$ & 1 & 3 & 211.205 & - & - & $\bullet$ & - & - & 22.860 & 29.440 \\
\hline 7 & 1 & 2489 & $2 l$ & & 89.134 & $7.1>3$ & 0.085 & - & - & - & & 850 \\
\hline$?$ & 1 & 2482 & $2 ?$ & & R9.? ?ค & .2 .17 & 0.055 & 9.130 & - & - & & 29.840 \\
\hline 7 & 1 & 20.817 & 1 & & 95.795 & 5.9\%! & חת 7 . י & 5.7 & 9.968 & 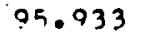 & 0 & $34 n$ \\
\hline & $?$ & 41 & 1. & 7 & $73 n .236$ & - & - & - & - & - & 24.940 & 79.725 \\
\hline a & ? & 2547 & 2 & 6 & 529.439 & - & - & - & - & - & 60 & $n$ \\
\hline a & ? & 2647 & 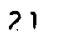 & & 67.878 & 7.657 & 7.959 & 68.07 & • & - & $9>n$ & 735 \\
\hline 1 & 7 & 47 & $?$ & & 67. ถก) & 7.769 & 7.9 .75 & $7 . ? 8 ?$ &. & - & 370 & 72.0 \\
\hline P. & 7 & 2547. & 31 & . & $75 . i 67$ & $\therefore 819$ & 4.819 & 74.765 & 75.227 & 74.8 & 90 & 29.773 \\
\hline & $?$ & $\because 5$ & 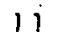 & 5 & 42.7 & • & & - & 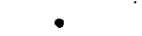 & & $3 n$ & 775 \\
\hline 9 & 1 & 2805 & ?. & 5 & 4.32 & - & - & - & - & • & & $6 n$ \\
\hline ? & 1 & 305 & 1 & & 549 & 1.503 & 1.479 & . & - & - & 40 & 70 \\
\hline ) & 1 & $P 4 \cap 5$ & $?$ & & 23 & $1.7 \mathrm{~cm}$ & 1.52 .5 & - & - & - & 50 & 960 \\
\hline 9 & 1 & 2405 & 31 & & 995 & 0.106 & $70.0 \cap 3$ & 69.844. & 9.8 & $7 n$. & 140 & 965 \\
\hline & 1 & $? 1$ & 1 & 5 & 34 & $\bullet$ & $\bullet$ & & & & 30 & 95 \\
\hline n & $!$ & 3121 & 17 & $\theta$ & 457 & - & - & - & & - & $n$ & $n$ \\
\hline$n$ & 1 & ${ }^{2} 12.1$ & 71 & & 698 & 59.650 & 60.805 & 69.711 & - & - & $5 n$ & 590 \\
\hline$n$ & 1. & $31 ? .1$ & ?.? & & 10 & 9.85 .3 & 69.850 & 60.769 & - & - & 40 & 575 \\
\hline n & 1 & 3121 & 31 & & 12 & $3.4: 6$ & 83.668 & 83.669 & 83.605 & 8.3. & 50 & $58 n$ \\
\hline & $?$ & & $i$ & $=$ & & - & - & - & & & & ח \\
\hline 1 & $?$ & 187. & $?$ & $=$ & 53 & - & - & - & • & - & 0 & 490 \\
\hline 1 & $?$ & $318 \%$ & 21 & & 35 & $? .216$ & 62.479 & 62.360 & - & - & 40 & 29.500 \\
\hline 1 & $?$ & 182 & 22 & & 504 & 2.459 & 2.590 & 62.597 & • & • & 30 & 485 \\
\hline 1 & $?$ & 87 & 31 & & 76 & 5.491 & 5.58 & 75.6 & 75. & 7 & 80 & 495 \\
\hline ? & 1 & 95 & 1 & $a$ & 04 & - & - & • & 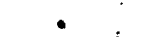 & - & $n$ & 410 \\
\hline$?$ & $i$ & 295 & 12 & 5 & 76 & - & - & - & - & - & $6 n$ & $+4 n$ \\
\hline ? & 1 & 2705 & 21 & & .700 & 1.1 .3 & $1.3 \cap 8$. & $71 .>87$ & 1.7 & - & $6 n$ & 20.420 \\
\hline ? & 1 & 95 & 2.? & & $4 n$ & .147 & 1.115 & $? 1 . ?$ & 1.178 & $\bullet$ & $6 n$ & $? 9.440$ \\
\hline 27 & $?$ & 95 & $?$ & & 5 & K.211 & $6 .>85$ & $75: ?$ & ?.? & & SO & 440 \\
\hline 72 & 1 & 3735 & $3 ?$ & & 265 & 6.251 & - & - & - & 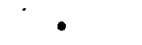 & 3.660 & 9.440 \\
\hline 3 & 1 & int & 11 & $\dot{b}$ & & - & - & . & & & & 90 \\
\hline 3 & 1 & 56 & 12 & 5 & & 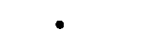 & - & - & - & - & 60 & 190 \\
\hline 3 & 1 & 7364 & 21 & & & is 9.945 & $9 . \cap>$ & 0 & 49.9 & 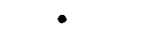 & & 900 \\
\hline 3 & 1 & 3266 & 2? & & & 3.918 & 9.08 & 49.8 & .0 & $\bullet$ & 40 & 90 \\
\hline 33 & 1 & 3.66 & 31 & & $44^{\circ}$ & 61.371 & 31.320 & 61.485 & 61.042 & $61 \cdot 3$ & 10 & 29.790 \\
\hline 3 & $\cdot 1$. & 3766 & $3 ?$ & & 483 & 51.771 & : & - & - & - & 3.110 & 29.790 \\
\hline 4 & ? & 64 & 11 & a & & & & & • & - & 80 & $47 n$ \\
\hline 46 & 2 & 6 & 17 & 6 & 34 & - & - & 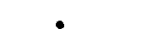 & - & . & & 460 \\
\hline 4 & ? & $3<60$ & $? !$ & & $n ?$ & 9.6 . & .5 & 40.5 & .5 & . & 0 & 475 \\
\hline & $?$ & & 27 & & & .5143 & .6 & 49.664 & - $6 ?$ & & $5 / 40$ & 29.455 \\
\hline
\end{tabular}




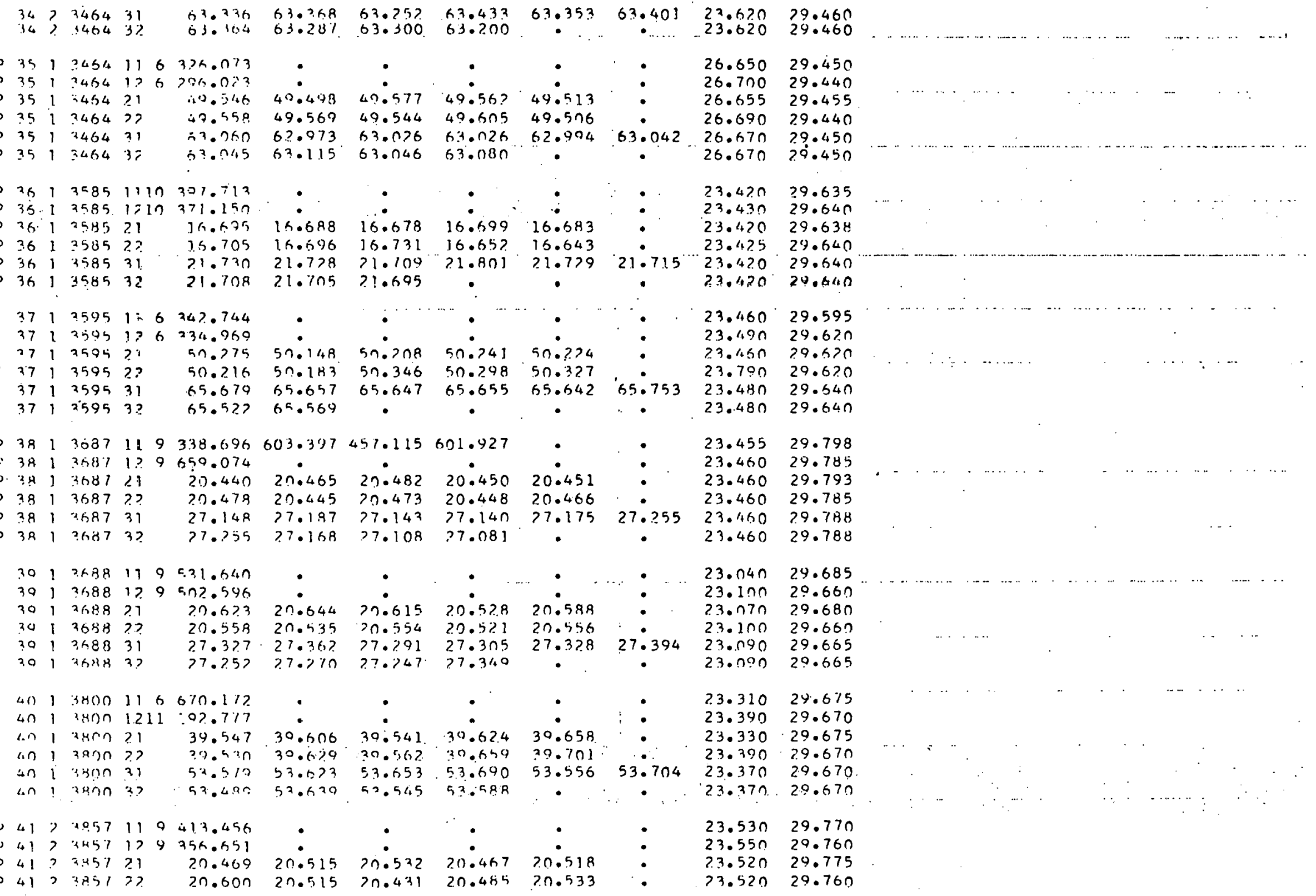




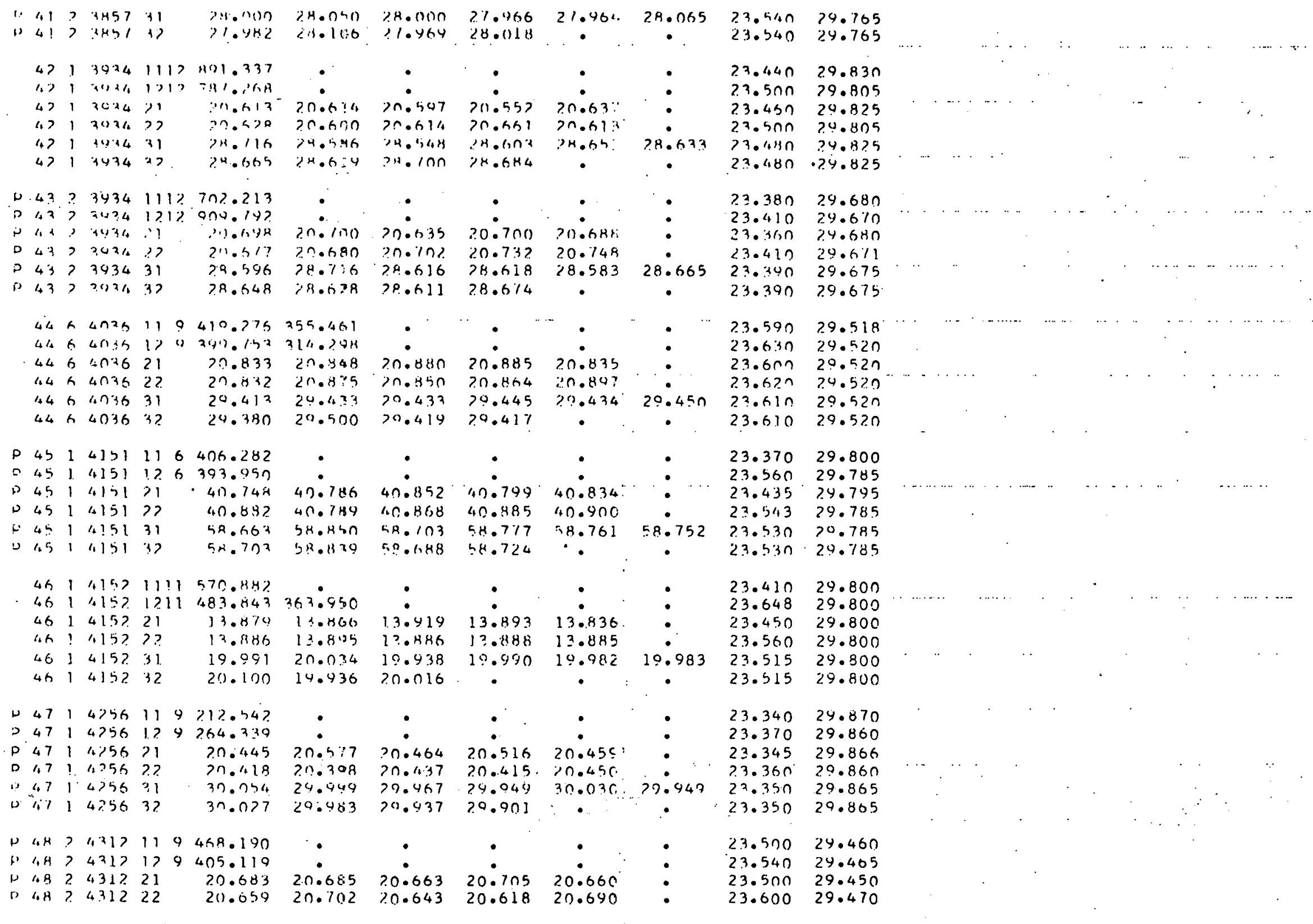




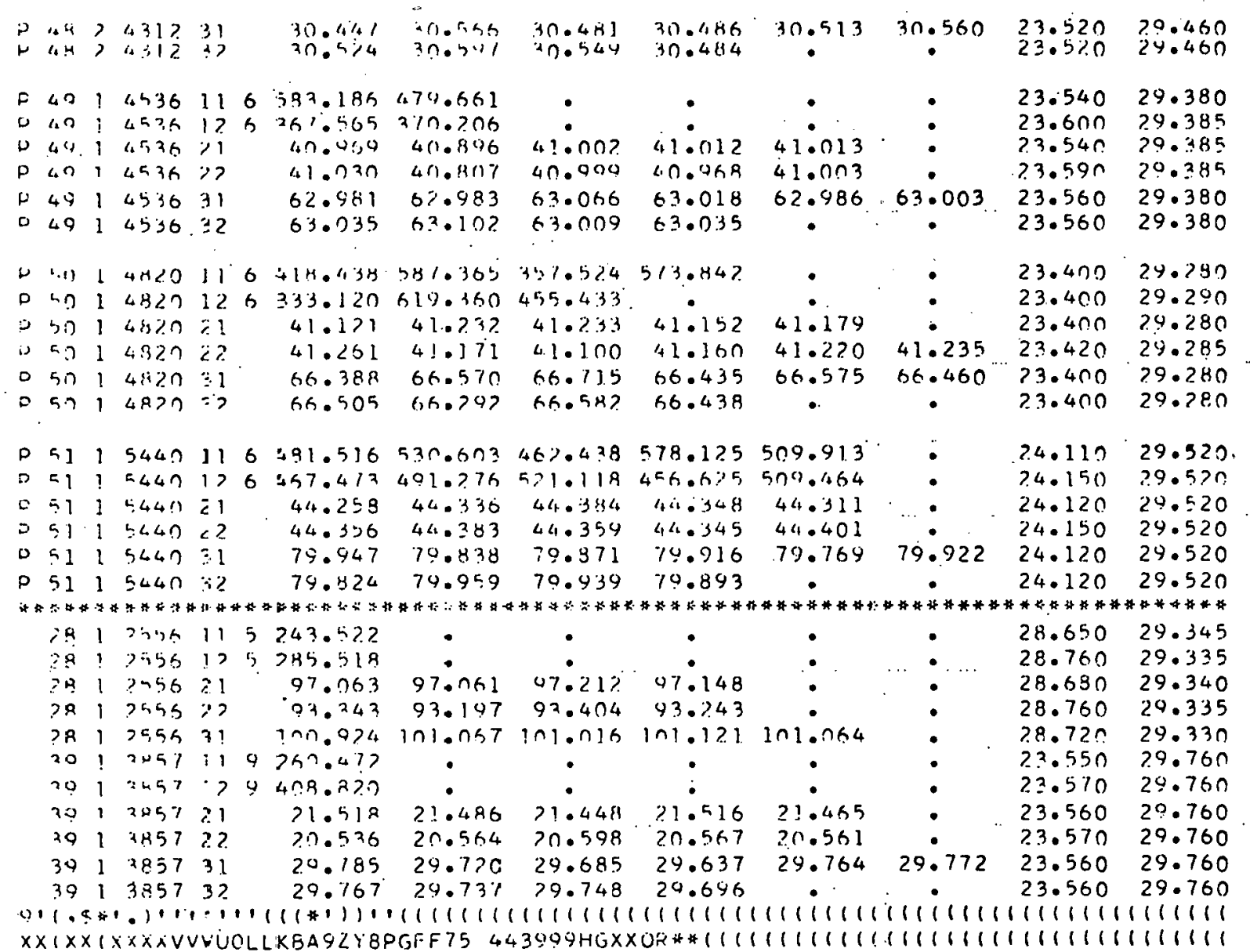


TABLE 2

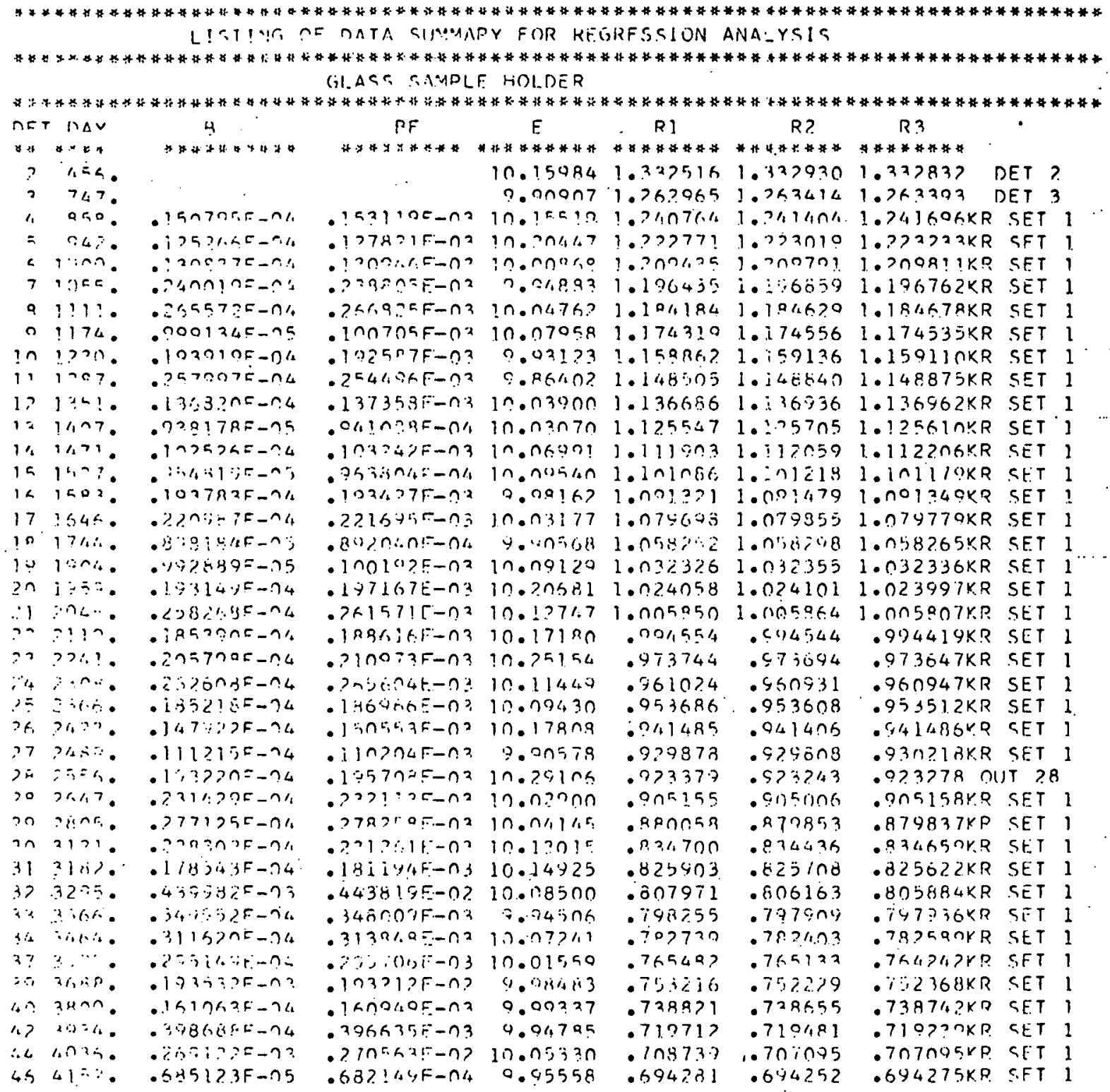




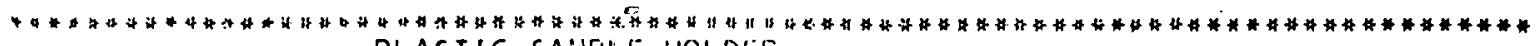

PLACTIC CABISLE HOLDFR

\begin{tabular}{|c|c|c|c|c|c|c|c|c|}
\hline 100,4 & 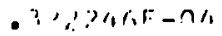 & $.2241 \therefore 31-0 . ?$ & 10.19123 & $.7057,5$ & .7056 .73 & .785550 KR & SET & 1 \\
\hline$\therefore:$ in: & - $\lg ] \ln (\mathrm{f} F-\cap i$ & - 71$\} 1: 1+i 1-n+$ & in.nofises & $.76,4171$ & $-7 \ln 10$ & - TGOTAGKR & SLT & $i$ \\
\hline 497. & . 1 idyin & - $175, n: \theta, F-\infty>7$ & 0.9117 & $75 \times 14 n$ & $.7 \div 221,9$ & $.7522714 \mathrm{RP}$ & SET & $i$ \\
\hline & . $\because 11, P F-n 3$ & . 260 ?ogat-no & ? ofitra & .7??ח & $.7^{7} \cap 0619$ & $.7 ? 072 n Y P$ & SET & 1 \\
\hline 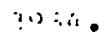 & . $1+$ ZnS $\} ; F-\cap 4$ & . $43 n>\sin F-n^{2}$ & n.sin & .7 .977 .20 & .737408 & $.7325 .7 \% 0$ & SF.T & 1 \\
\hline $\begin{array}{l}41.1 . \\
4259 .\end{array}$ & $\begin{array}{l}024 \cdot 238,2 F-74 \\
424299 F-\cap 3\end{array}$ & $\begin{array}{l}.2484+4 t-n 3 \\
4213=5 \mathrm{~F}-027\end{array}$ & 4.21044 & - 693047 & .674148 & - $67500 \cap K P$ & SET & 1 \\
\hline $431 ?$. & 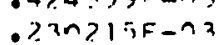 & . $>318>n F-02$ & $\begin{array}{l}\% .0360 \\
10.07066\end{array}$ & $\begin{array}{l}.682394 \\
.677271\end{array}$ & $\begin{array}{l}.079612 \\
.675778\end{array}$ & $.079559 K R$ & SET & 1 \\
\hline 4511. & 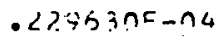 & $.2310015-n 3$ & $10.0987 n$ & $.65 n n 991$ & .649761 & $.649861 \mathrm{KR}$ & SET & 1 \\
\hline $482:$ & $.2 n 0704 E-04$ & $.212441 E-113$ & 10.12756 & .619400 & .619071 & $.619098 \mathrm{KR}$ & SET & 1 \\
\hline 0 . & $.199767 F-94$ & $\cdot 2 n 1] \& 2 F-03$ & 10.07074 & $.55513 n$ & .534735 & . $5547 n 7 K R$ & SET & 1 \\
\hline
\end{tabular}

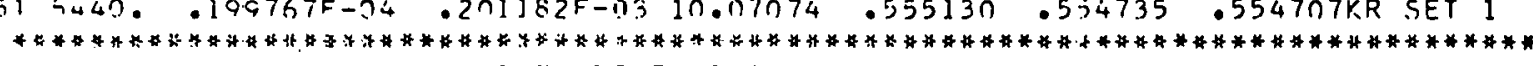

P.FMIOVFD DFTFRVINIATION!S
$\prod_{0.057}^{n}$
$314262-03$
0.19852
$4362361.436452 \cdot 1.438178$ DET 1

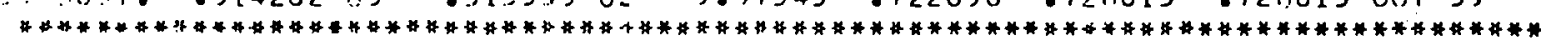


TA.BLEE 3

IHDIVIOUAL IMLF-LIFE DETERMINATIONS WITII-SUMHURY STATISTICS

TE

lis

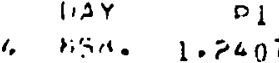

n )1611: 1.20:7456

7 16. 1.196434

H 11.11. 1.1314140

4 1174. 1.174314

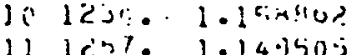

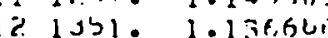

$131407 \cdot 1.125547$

1, 1 .

is $15,>7$

f) 1 is: 2 .

$1 i !+. .+6$.

i: $1 ? ; 0$

101160

3i $3: 40^{\circ}$

27. $11: 9$

$2 \therefore 8410$

24. $25,14$.

J) 30 .

(2) 2423

a! $26+7$.

31. जादा.

$3 ; 31 \because ?$.

3c. $3 x$ ista

363464.

$353<64$.

उt $35+5$.

37 35?5.

$3 \div 36+4$.

P 4) $z^{4}=7$.

4? 3434.

44 10

44 inlis.

$4 ! 2+151$.

$46 \cdots+152$.

P 47 40.5ir.

F 4\$ 43:7.

P. 40 4.53\%.

P $5(14$ 4 तो).

1. 111903

I.

$1007 y+4 i$

0
10

1.

is 2456

i)7374"

061004

94is lit;

(थ) 1495

195:

-4n5ly

- rivgojus

- 3476 r.

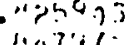

74 740

$7 k-7 j \%$

- Th5cos

-7afizi

- 7t-56is?

-75314:"

..7?.1n

1 jeind?

$.7320 i 1$

.71971 ?

7011731

7 nब173

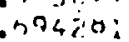

. t.117jats.

67727:

. $60,0 ? 171$

की 44011

. 'र55) 3.

$.5,54735$

$1.014041 .21+199$ 1.

$A$
$Y \rightarrow L-1)$ ME

\section{E.}

- 1531148-03 10.15519

$-1270715-03 \quad 10.21) 447$

$.130746 t .003$

$13 a^{4} 312-04$

- 4 (n)

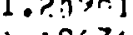

1.196752

$1.1: 2467: 4$

1. 174535

$.9991 .3+1.003$

- $193+14 t-04$

$.257977 t-04$

. 13 तुSUIt-04

$.93 H(7 \mathrm{RL}-155$

- 1 n?jzotr-04

.954 d $14 t-05$

- 193 ! Hate -04

- $2207411-04$

- 89H1:34t-u5

$.99203 y t-05$

- l) $31448-04$

. ग5RCSAR. 04

$.1853 y_{11} t-04$
.$? 051$ jut.-104

. $2620,3 k t-04$

i $15010 t-04$

- $1479 ? 2.0+04$

- $111<15 t-04$

$.231+24 r-1)^{4}$
$.277+2 t-114$

- 225130?t-0't

.17 万4jatr-nt

$.439 \%$ iart-03

3.945 $35-01+$

. 311 njert-na

-3P2.24tE-n+

- $295142 t-n 4$

$175 d_{11} t-03$

- 19 3ajar -03

.16196.jt-04

26) $125 t-0.3$

- उदhóhar-1la

.

$.249 \% 87 \mathrm{r}-04$

$.64512 .96-0,5$

$024 j 90 t-03$

-?.3riejor -0

$.020) 318,5-04$
$.50)$

- 6491101

- 19074

.554707

$238.505-1) 3 \quad 9.94 A 83$

$.266325 t-03 \quad 10.0476$ ?

$.10 n 10$ TE-03 10.0795H

-192.SR7E-03 9.9312.3

$.254+9 A E-J 3 \quad 9.86402$

177.35月E-03 10.03900

$9410 B A E-04 \quad 10.03071$

.10324 TE-U3 10.05991

.963ito4E-04 lin.09540

$.193427 E-03 \quad 9.98162$

. 10.03177

201010-04 9.9056A

$100192 E-03 \quad 10.09129$

$.297167 E-03 \quad 10.20681$

- 18 BLI6E-03 111.177180

$.210 .73 F_{0}-03 \quad 10.25154$

$.265004 E-03 \quad 10.11449$

- 1HEYOGF-03 10.09430

- 150 S5.3E-03 10.1780B

$.110204 E-03 \quad 9.9057 R$

$.23 ? 113 \mathrm{~F}-03 \quad 1 \mathrm{n} .02900$

C78,58E-03 10.04145

1R11345-13 10.13015

$.443 \mathrm{H} J O E-1) 2$ 10.01500

.34HOOOE-113 9.945OA

-31334nE-0.3 $10.0^{7} 241$

7R1H57E-03 $10.1{ }^{3} 193$

.29510 RE-03 10.01559

$.175030 E-02$ 2.9. 95717

$19.3212 E-02$

-16

$260295 t^{\circ .00}$ ?

9.934 त3

9.99337

$9.9675 \mathrm{~A}$

$6035 F-0.3 \quad 9.947 A 5$

$.420244 t .003$

. $27.0503 F_{0}$. U?

-24RAYAF -0.3

.6B?14UE-U4

9.99320

10.05330

9.95848

9.95558

$.2310205-02 \quad 0.92865$

2319010 10.07066

$.231901 E=03$
$.212441 F-03$
$.0201165 E .03$

\begin{tabular}{rr}
$.212441 F-013$ & 10.12766 \\
$.201152 E .003$ & 10.07074 \\
\hline
\end{tabular}

\begin{tabular}{|c|c|c|}
\hline$(.5) 1$ & $K(.5) 2$ & $K(.5) 3$ \\
\hline $\begin{array}{l}11.054 \\
11.034 \\
10.967\end{array}$ & $\begin{array}{l}10.797 \\
10.7191 \\
10.736\end{array}$ & $\begin{array}{l}10.013 \\
110.791 \\
10.736\end{array}$ \\
\hline $\begin{array}{l}0.846 \\
0.853\end{array}$ & $\begin{array}{l}10.674 \\
10.653\end{array}$ & $\begin{array}{l}10.668 \\
10.655\end{array}$ \\
\hline $\begin{array}{l}0.991 \\
0.805\end{array}$ & $\begin{array}{l}10.7 R 8 \\
10.620\end{array}$ & $\begin{array}{l}10.786 \\
10.618\end{array}$ \\
\hline $\begin{array}{l}.95 ? \\
.487\end{array}$ & $\begin{array}{l}10.675 \\
10.715\end{array}$ & $\begin{array}{l}10.676 \\
10.715\end{array}$ \\
\hline $\begin{array}{r}.88^{4} 0 \\
.834 \\
.832\end{array}$ & $\begin{array}{l}10.711 \\
10.673 \\
10.677\end{array}$ & $\begin{array}{l}10.707 \\
10.678 \\
10.675\end{array}$ \\
\hline $\begin{array}{r}.865 \\
.874\end{array}$ & $\begin{array}{l}10.715 \\
10.729\end{array}$ & $\begin{array}{l}10.710 \\
10.726\end{array}$ \\
\hline $\begin{array}{l}0.765 \\
0.809\end{array}$ & $\begin{array}{l}10.623 \\
10.740\end{array}$ & $\begin{array}{l}10.526 \\
10.739\end{array}$ \\
\hline $\begin{array}{l}.917 \\
.823 \\
.069\end{array}$ & $\begin{array}{l}10.791 \\
10.703 \\
10.752\end{array}$ & $\begin{array}{l}10.787 \\
10.701 \\
10.74 A\end{array}$ \\
\hline $\begin{array}{l}870 \\
18 \geqslant 9 \\
89 ?\end{array}$ & $\begin{array}{r}10.75 \mathrm{~A} \\
10.720\end{array}$ & $\begin{array}{l}10.756 \\
10.720\end{array}$ \\
\hline $\begin{array}{l}0.39 ? \\
0.815 \\
0.793\end{array}$ & $\begin{array}{l}10.785 \\
10.712 \\
10.693\end{array}$ & $\begin{array}{l}10.782 \\
10.714 \\
10.703\end{array}$ \\
\hline $\begin{array}{r}.909 \\
.796 \\
.840\end{array}$ & $\begin{array}{l}10.712 \\
10.704 \\
10.755\end{array}$ & $\begin{array}{l}10.715 \\
10.703 \\
10.760\end{array}$ \\
\hline 0.8141 & $\begin{array}{l}10.759 \\
10.642\end{array}$ & $\begin{array}{l}10.756 \\
10.676\end{array}$ \\
\hline $\begin{array}{l}0.903 \\
0.753\end{array}$ & $\begin{array}{l}10.722 \\
10.581\end{array}$ & $\begin{array}{l}10.723 \\
10.685\end{array}$ \\
\hline 0.831 & 10.752 & 10.751 \\
\hline 0.799 & 10.723 & 10.722 \\
\hline $\begin{array}{l}0.770 \\
0.757\end{array}$ & $\begin{array}{l}10.674 \\
10.682\end{array}$ & $\begin{array}{l}10.674 \\
10.682\end{array}$ \\
\hline $\begin{array}{l}0.772 \\
0.777\end{array}$ & $\begin{array}{l}10.644 \\
10.709\end{array}$ & $\begin{array}{l}10.587 \\
10.710\end{array}$ \\
\hline 0.780 & 10.645 & 10.697 \\
\hline $\begin{array}{l}0.734 \\
0.749\end{array}$ & $\begin{array}{l}10.667 \\
10.731\end{array}$ & $\begin{array}{l}10.662 \\
10.732\end{array}$ \\
\hline .772 & 10.677 & 10.677 \\
\hline $\begin{array}{l}.78 ? \\
.769\end{array}$ & $\begin{array}{l}10.717 \\
10.705\end{array}$ & $\begin{array}{l}10.721 \\
10.709\end{array}$ \\
\hline $.78_{1}$ & 10.666 & 10.665 \\
\hline .813 & $10.7 ? 4$ & 10.727 \\
\hline .787 & 10.727 & 10.728 \\
\hline .804 & 10.746 & 10.746 \\
\hline & 10.735 & 10.734 \\
\hline
\end{tabular}

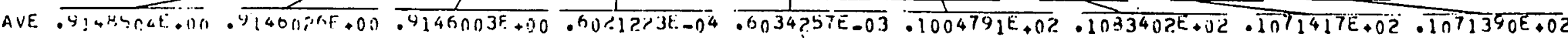

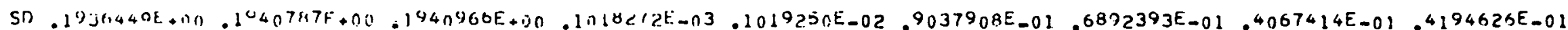

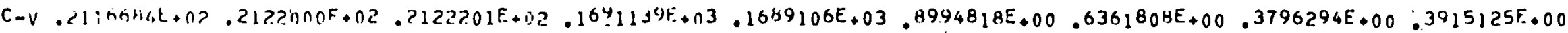


WITHIN RUH AVERAGES, STAMDARD DEVIATIOHS AND COEFFICIENTS OF VARIATION

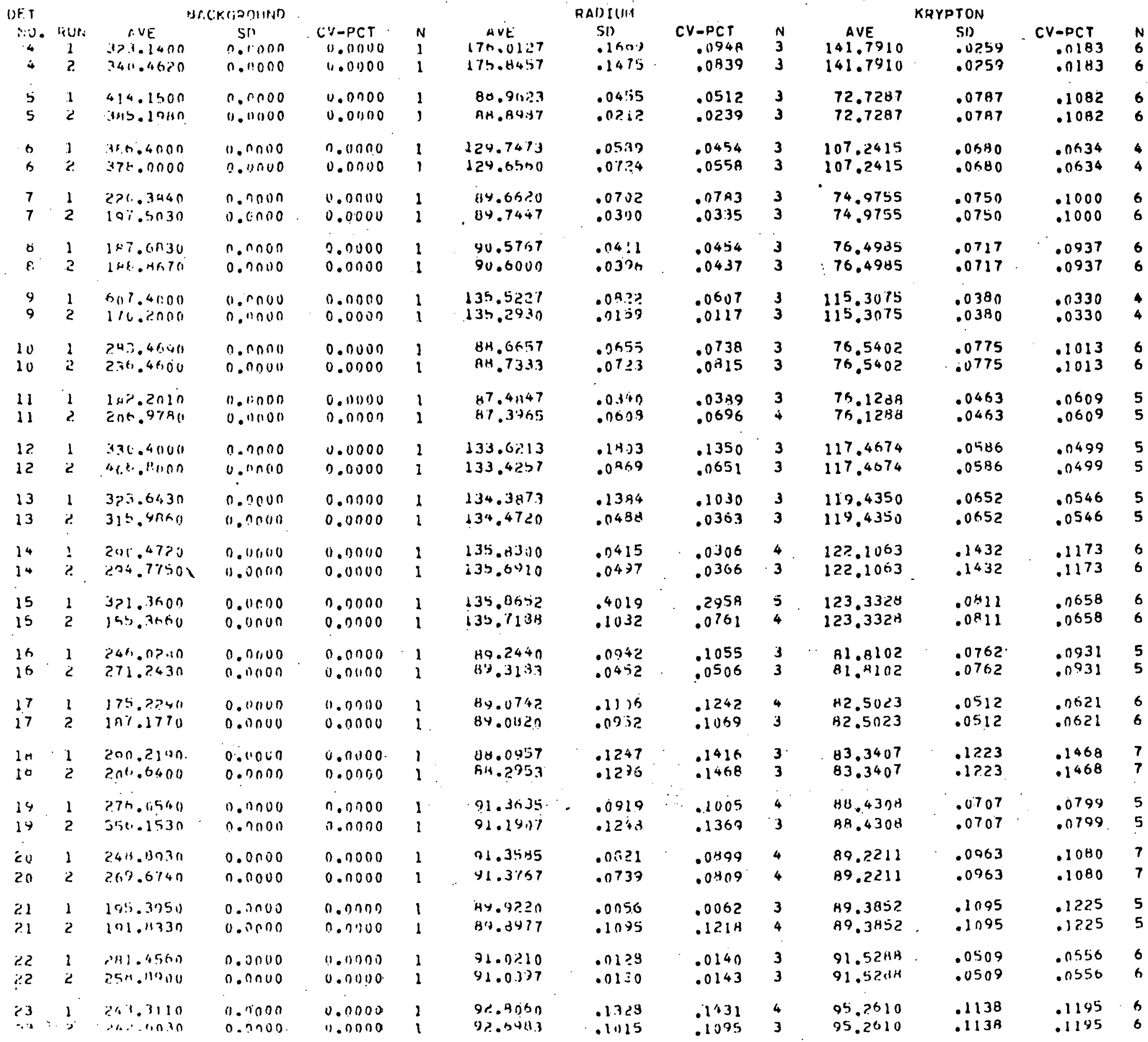




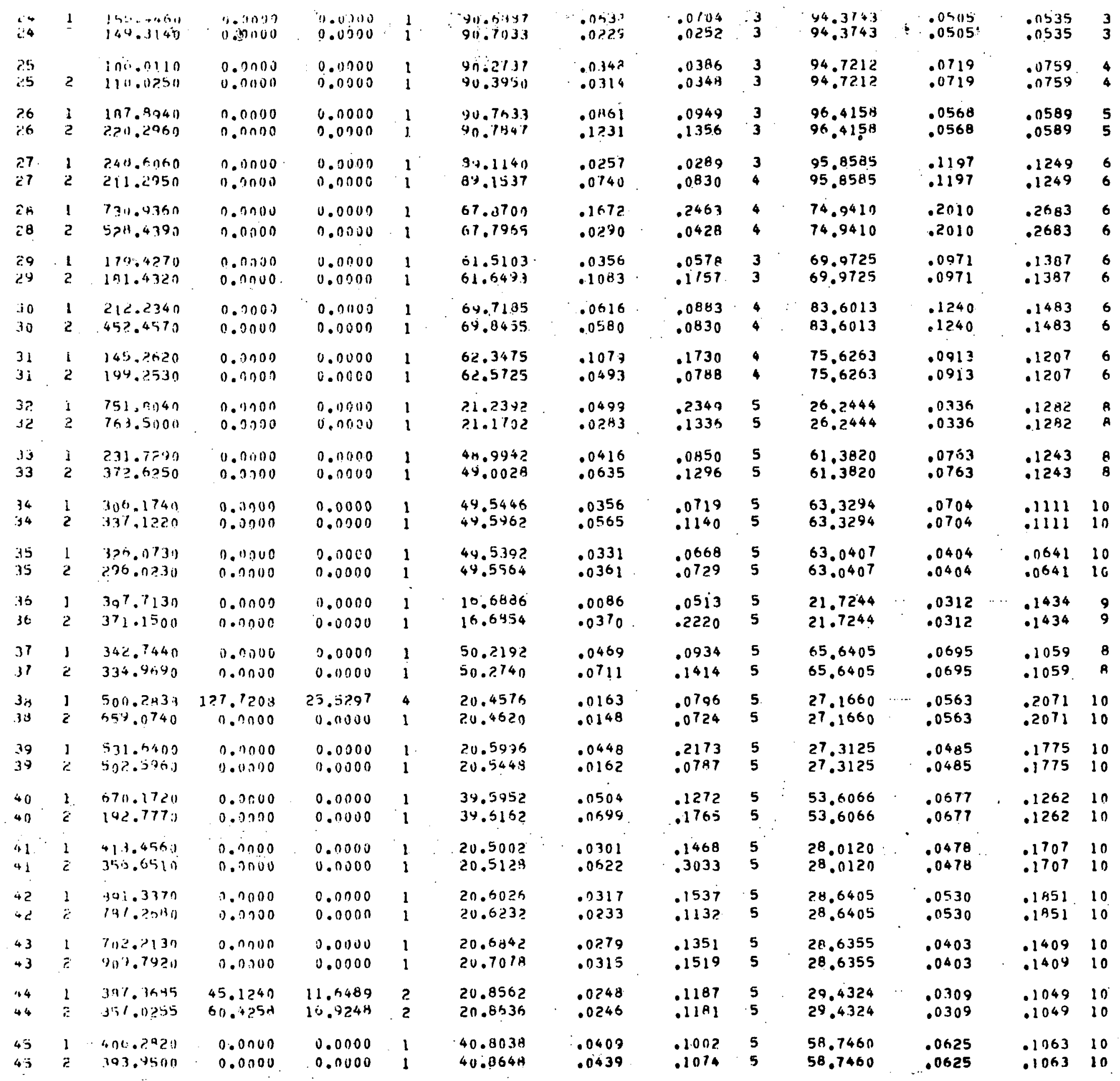




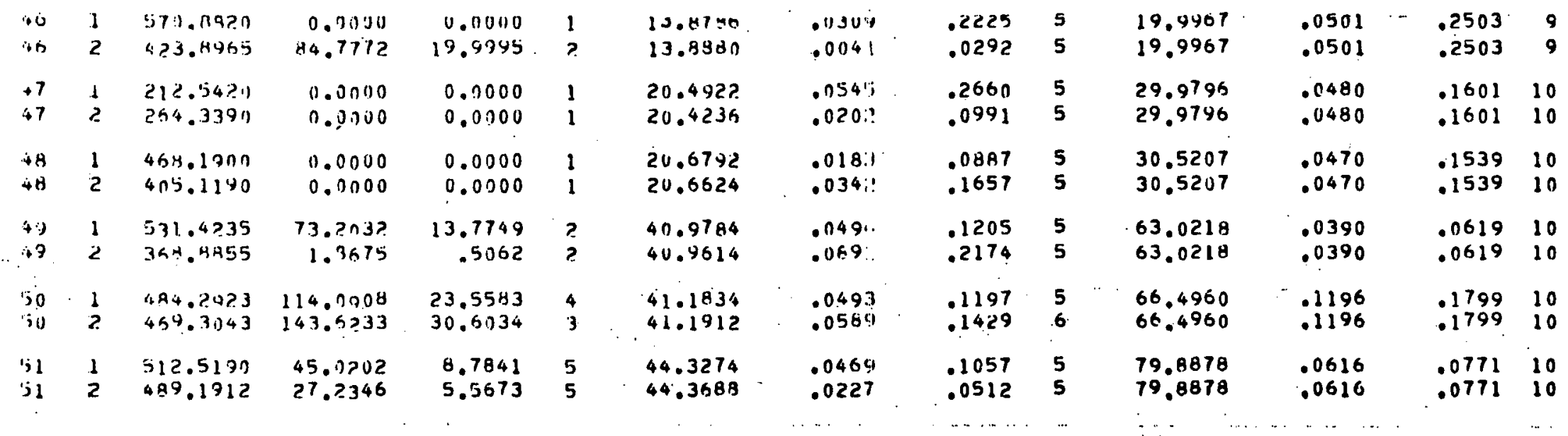


TAlitL 5

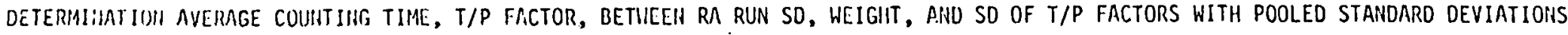

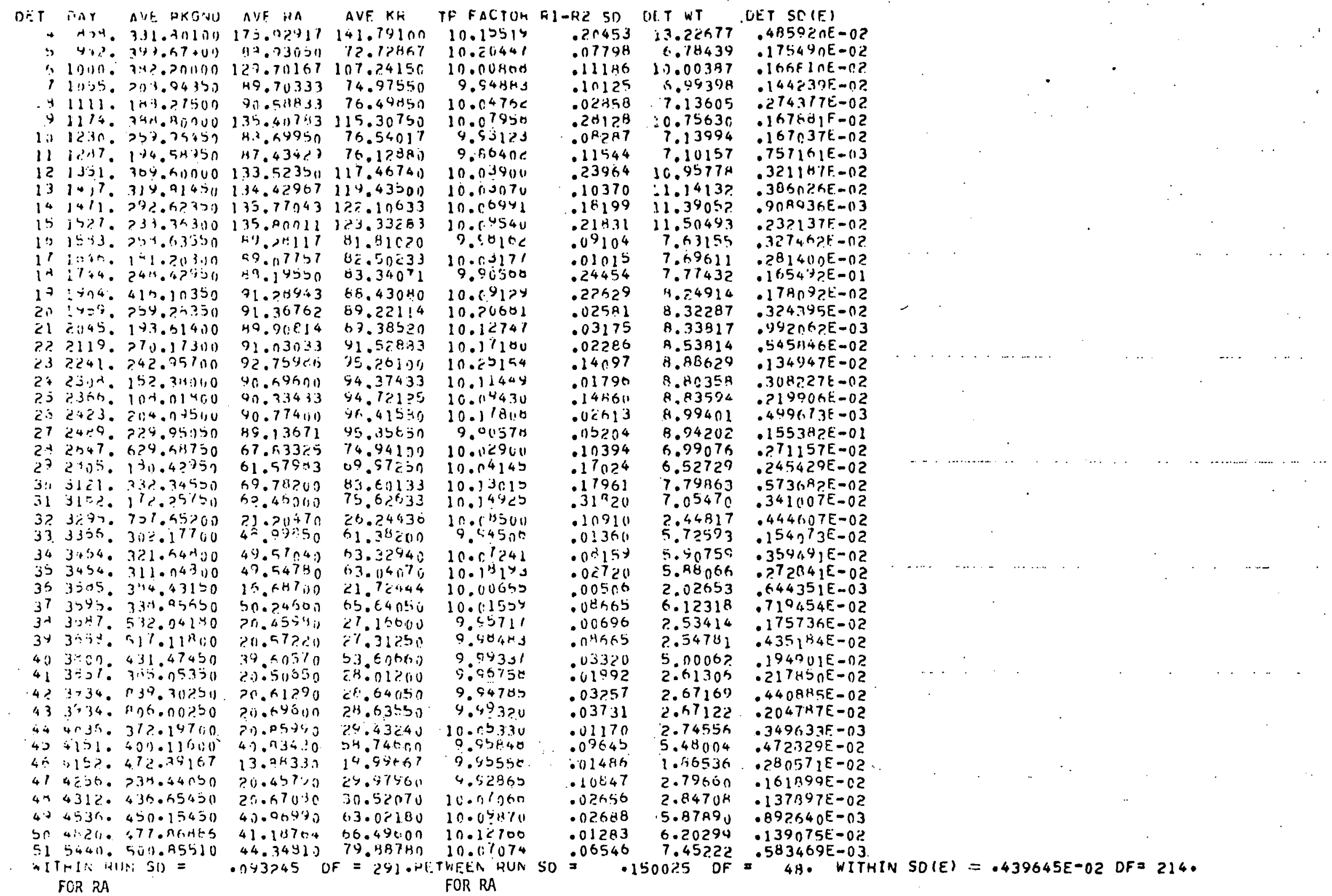


No. of Copies

OFFSITE

1 AEC Chicago Patent Group

U.S. Atomic Energy Commission 9800 South Cass Avenue Argonne, Illinois 60439

A. A. Churm

2 AEC Technical Information Center

1 AEC Division of Technical Research

U.S. Atomic Energy Commission Washington, DC 20545

T. W. Buttery
No. of Copies

ONSITE

1 AEC Richland Operations Office

P.F.X: Dunigan Jr./

B. J. Melton

24 Battelle-Northwest

J.W. Johnston

W.L. Nicholson (20)

Technical Information Fites (3) 